\title{
Biomarkers of intake for tropical fruits
}

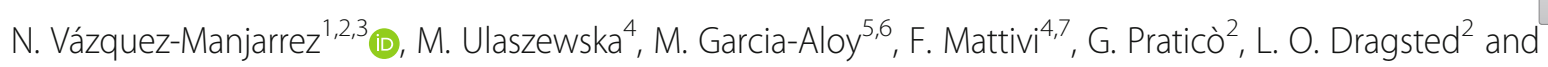

C. Manach ${ }^{1 *}$

\begin{abstract}
Consumption of fruit and vegetable is a key component of a healthy and sustainable diet. However, their accurate dietary assessment remains a challenge. Due to errors in self-reporting methods, the available dietary information is usually biased. Biomarkers of intake constitute objective tools to better reflect the usual or recent consumption of different foods, including fruits and vegetables. Partners of The Food Biomarker Alliance (FoodBall) Project have undertaken the task of reviewing the available literature on putative biomarkers of tropical fruit intake. The identified candidate biomarkers were subject to validation evaluation using eight biological and chemical criteria. This publication presents the current knowledge on intake biomarkers for 17 tropical fruits including banana, mango, and avocado as the most widely consumed ones. Candidate biomarkers were found only for banana, avocado, and watermelon. An array of banana-derived metabolites has been reported in human biofluids, among which 5hydroxyindole-acetic acid, dopamine sulfate, methoxyeugenol glucuronide, salsolinol sulfate, 6-hydroxy-1-methyl-1,2,3, 4-tetrahydro- $\beta$-carboline-sulfate, and other catecholamine metabolites. Their validation is still at an early stage, with insufficient data on dose-response relationship. Perseitol and mannoheptulose have recently been reported as candidate biomarkers for avocado intake, while the amino acid citrulline has been associated with watermelon intake. Additionally, the examination of food composition data revealed some highly specific phytochemicals, which metabolites after absorption may be further studied as putative BFI for one or several tropical fruits. To make the field move forward, untargeted metabolomics, as a data-driven explorative approach, will have to be applied in both intervention and observational studies to discover putative BFls, while their full validation and the establishment of dose-response calibration curves will require quantification methods at a later stage.
\end{abstract}

Keywords: Banana, Watermelon, Avocado, Pomegranate, Tropical fruit, Biomarkers, Intake

\section{Background}

More than 800 tropical fruits have been described, but only a small number are widely consumed [1]. Geographically, tropical fruits have their origin in the tropics of Cancer and Capricorn in the north and south of the equator covering most of the tropical and subtropical areas of Asia, Africa, Central America, South America, the Caribbean, and Oceania. In comparison to the temperate fruits such as apple, pears, and berries, tropical fruits are gaining terrain in global production and trade due to a growing demand from consumers. As an example, the production of avocados in the top producing

\footnotetext{
* Correspondence: claudine.manach@inra.fr

${ }^{1}$ Human Nutrition Unit, Université Clermont Auvergne, INRAE, F-63000

Clermont-Ferrand, France

Full list of author information is available at the end of the article
}

country, Mexico, rose 1900\% between 1961 and 2017 [2]. Moreover, mango availability was reported to increase from $1 \mathrm{~kg}$ per capita in 2007 to $1.8 \mathrm{~kg}$ per capita in 2017 in the USA, and from $0.4 \mathrm{~kg}$ to $0.7 \mathrm{~kg}$ in the European Union [3].

Several tropical fruits have been studied for their effect in human health due to their content in specific bioactive compounds. Of these, pomegranate has received much attention in recent years. A recent meta-analysis of 8 randomized controlled trials (RCT) $(n=574)$ showed that the intake of pomegranate juice reduces systolic $(-4.96,95 \%$ $\mathrm{CI}-7.67$ to $-2.25 \mathrm{mmHg}, P<0.001)$ and diastolic blood pressure $(-2.01,95 \% \mathrm{CI}-3.71$ to $-0.31, P=0.021)$ [4]. The effects of pomegranate on human health, including LDL-cholesterol, triglycerides, and glucose reduction, have

(c) The Author(s). 2020 Open Access This article is licensed under a Creative Commons Attribution 4.0 International License, which permits use, sharing, adaptation, distribution and reproduction in any medium or format, as long as you give appropriate credit to the original author(s) and the source, provide a link to the Creative Commons licence, and indicate if changes were made. The images or other third party material in this article are included in the article's Creative Commons licence, unless indicated otherwise in a credit line to the material. If material is not included in the article's Creative Commons licence and your intended use is not permitted by statutory regulation or exceeds the permitted use, you will need to obtain permission directly from the copyright holder. To view a copy of this licence, visit http://creativecommons.org/licenses/by/4.0/. 
been ascribed to its content in ellagitannins and to urolithins, their gut microbiota metabolites [5, 6].

Unlike pomegranate, information regarding the health effects of other tropical fruits, including the widely consumed banana, is remarkably scarce. To tackle this, wellconducted human studies with randomized controlled designs and prospective cohort studies with accurate dietary assessment will be needed.

Food Frequency questionnaires (FFQs) are widely used to assess fruit intake, but they have several disadvantages. It has been shown that the intake of fruits and vegetables $(F \& V)$ is often over-reported when assessed by food frequency questionnaires, due to social desirability bias [7]. Moreover, dietary questionnaires rarely evaluate the fruit consumption down to specific foods and varieties, and even in detailed FFQs, not much attention is given to tropical fruits, because of their diversity and low average intake in most studied populations compared to other fruits. In Western countries, except for banana and avocado, tropical fruits are often not considered in the FFQs or they are integrated in a more or less heterogeneous food group. For example, watermelon and melon are constantly listed together $[8,9]$ hindering the assessment of their respective intakes. In some producing countries such as Singapore, Mexico, and Brazil, FFQs consider tropical fruits including guava, kiwi, papaya, dragonfruit, watermelon, dates, and persimmon [10-12], although in an inconsistent manner. One could argue that the well-designed dietary instruments may suffice to obtain accurate intake information of tropical fruits. However, self-reporting methods will always be subject to imprecision associated to recall errors, difficulty to assess portion size, and social desirability bias. Furthermore, listing all tropical fruit individually would significantly expand the questionnaires and increase participant burden. The use of dietary biomarkers, whose associated errors are independent from that of questionnaire instruments, has the potential to assist in accurately determining dietary intake, and hence better unravel the associations between diet and human health.

BFIs originate from compounds that are specific for a given food or food group, and become bioavailable after their consumption [13]. Plasma vitamin $C$ and carotenoids increase after tropical fruit intake and are biomarkers commonly used to assess the total intake of F\&V [14]. However, their use is not without limitations. The bioavailability of carotenoids fluctuates according to the alongside diet or food preparation, e.g., simultaneous intake of fat enhances their absorption $[15,16]$. Furthermore, plasma vitamin $\mathrm{C}$ concentration exhibits saturation kinetics, meaning that its collinearity with dietary intake stops at a certain point, especially in wellnourished subjects where baseline concentrations are observed at $\sim 60 \mu \mathrm{mol} / \mathrm{L}$ [17]. Plasma vitamin $C$ is further challenged by several external factors including preanalytical conditions such as sample handling, temperature, and conditions of storage [18].

The Food Biomarkers Alliance (FoodBAll JPI-project; www.foodmetabolome.org), in an effort to collate the most comprehensive panel of BFIs as possible for over 140 commonly consumed foods, has conducted a series of reviews of the literature according to the guidelines established by the consortium [19]. The obtained BFIs are evaluated according to eight defined criteria to qualify their applicability as BFIs in further nutritional and health-related research [20]. The vision is to develop analytical methods that could quantify in a cost-effective way a battery of dietary biomarkers to validate or complement dietary questionnaires. Within the FoodBall initiative, the objectives of the present work are as follows: (1) retrieve from an extensive literature search the compounds currently used as BFIs for tropical fruits and those which are specific enough to represent putative BFIs and (2) outline the available knowledge and provide the current level of validation of the collated candidate BFIs for tropical fruits.

\section{Methods}

\section{Selection of food groups}

For the present review, 16 tropical fruits including the most consumed in the world according to FAO production and trading data were selected [3]. This review assesses the following fruits: dessert banana (Musa acuminata), mango (Mangifera indica), pineapple (Ananas comosus), papaya (Carica papaya), avocado (Persea Americana), pomegranate (Punica granatum), kiwifruit (Actinidia), lychee (Litchi chinensis), persimmon (Diasporos kaki), guava (Psidium guava), passion fruit (Passiflora edulis), acerola (Malpighia emarginata), dragon fruit (Hylocereus undatus), coconut (Cocos nucifera), watermelon (Citrullus vulgaris), muskmelon (Cucumis melo), and date (Phoenix dactylifera).

\section{Search for relevant BFIs research papers}

An extensive literature search was carried out to collect all available information on the already used or new putative BFIs for the selected fruits. The BFIRev protocol (Food Intake Biomarker Reviews) elaborated with the guidance of the PRISMA statement (Preferred Reporting Items for Systematic reviews and Meta-Analyses) and described in Pratico et. al. [19] was followed. Briefly, a primary search was performed in the three literature search databases, Scopus, PubMed central, and Web of Science, with the name of the specific fruit and its botanical genus, i.e., (Banana OR Musa*) OR (Mango OR Mangifera* OR Pineapple OR Ananas* OR Papaya OR Carica* OR Avocado OR Persea* OR Pomegranate OR 
Punica* OR Kiwi* OR Actinidia* OR Lychee OR Lichee OR Litchi* OR Persimmon OR Diospyros* OR Guava OR Psidium* OR Passion fruit OR Passiflora* OR Acerola OR Malpighia* OR Pitaya OR Pitahaya OR Dragon fruit OR Hylocereus* OR Coconut OR Cocus* OR Watermelon OR Citrullus* OR Muskmelon OR Melon OR Cantaloupe OR Cucumis* OR Phœnix dactylifera) along with the common keywords: AND (urine OR plasma OR serum OR excretion OR blood) AND (Human* OR men OR women OR patient* OR volunteer* OR participant*) AND (Biomarker* OR marker* OR metabolite* $^{*}$ OR Biokinetics OR Biotransformation OR Pharmacokinetics OR bioavailability OR ADME) AND (Intake OR meal OR diet OR ingestion OR administration OR consumption OR eating OR drink*). Keywords were used in the fields [Topic], [All fields], and [Article Title/Abstract/Keywords] for Web of Science, PubMed, and Scopus, respectively. All searches were carried out in March 2016 and updated in January 2019. A last search in April 2020 resulted in no new putative biomarkers. Only papers in the English language were considered eligible, and no restriction on the date of publication was applied. Articles showing results of human intervention studies (randomized controlled trials, single-dose, short-term or long-term studies) or observational studies (cohort, casecontrol, cross-sectional studies) were considered eligible. After removal of duplicates, a first selection of papers was performed according to the relevance of the abstract and title. Full texts were obtained for the selected articles and further assessed for eligibility according to their relevance for the identification of BFIs for all tropical fruits. Some of the publications found in the reference list of the selected articles were also included at this stage. Furthermore, for those tropical fruits for which no information in human studies was available, we carried out an additional search in food composition databases including, Dictionary of Food Compounds, FooDB and KNApSAck [21-23], and used the text-mining tools, Polysearch2 [24] and Coremine [25] medical online database, to identify specific compounds for each fruit that may be further investigated as putative BFIs [26].

\section{Characterization of candidate BFIs}

For each putative biomarker identified, a secondary search allowed to retrieve relevant information to assess its specificity, pharmacokinetics, dose-response relationship, robustness, and reliability, as well as the quality of its method(s) of analysis, in order to qualify its use as BFI according to the validating scheme established by Dragsted et al. [20].

The name of the putative biomarkers and their synonyms were queried in the literature search databases along with AND (biomarker* OR marker* OR metabolite* OR biokinetics OR biotransformation OR pharmacokinetics
OR bioavailability OR ADME). Additionally, the compounds were searched manually in the online databases HMDB [27], FooDB [22], Phenol-Explorer [28], Dictionary of Food Compounds [21], Duke's phytochemical and ethnobotanical databases [29], eBASIS [30], KNApSack [23], and PhytoHub [31] to determine all the possible dietary or metabolic origins of the candidate BFIs.

The list of candidate BFIs was reviewed and agreed upon all authors.

\section{Application of validation criteria}

According to the method of Dragsted et al. [20], a validation assessment procedure was applied on the candidate BFIs to assess their current status of validation and identify the missing information for full validation. The validation scheme is based on eight questions that encompass biological and chemical aspects: plausibility, dose-response, time-response, robustness, reliability, stability, analytical performance, and reproducibility (Table S1).

\section{Results and discussion}

A flowchart indicating the literature search and the review process is shown in Fig. 1. After removal of duplicates, the literature search yielded 1235 publications for the tropical fruits. Of these, 40 articles reported relevant information on putative biomarkers of intake. Five additional articles were selected from the reference list of the assessed publications or from the secondary search. A summary of the retained literature and the list of the specific candidate BFIs for tropical fruits are presented in Table 1 and Fig. 2. The level of validation of the candidate BFIs is shown in Table 2. For an exhaustive presentation of the results, a full list of all retained and nonretained compounds is given in Table S2, with the main reasons for inclusion or exclusion and the corresponding references.

\section{Banana biomarkers}

Banana, which is the second most-produced fruit in the world with 113 million tons and is among the three most consumed fruits in Europe [56, 57], certainly deserves specific attention for identifying an intake biomarker. The metabolite 5-hydroxyindole acetic acid (HIAA) was among the most studied compounds in association with banana intake. Of the 23 publications reviewed for this section, 10 reported the impact of banana intake on HIAA in urine (Table 1). HIAA originates from the catabolism of serotonin by the monoamine-oxidase (MAO, EC 1.4.3.4) and aldehyde dehydrogenase (ALDH, EC 1.2.1.3) enzymes. Besides its endogenous origin, serotonin can be provided in substantial amounts by several foods. Banana has a high serotonin content $(15 \pm 2.4 \mu \mathrm{g} / \mathrm{g}$ FW) along with nuts $(87-398 \mu \mathrm{g} / \mathrm{g})$, pineapple $(17 \pm 5.1 \mu \mathrm{g} / \mathrm{g} \mathrm{FW})$, plantain 


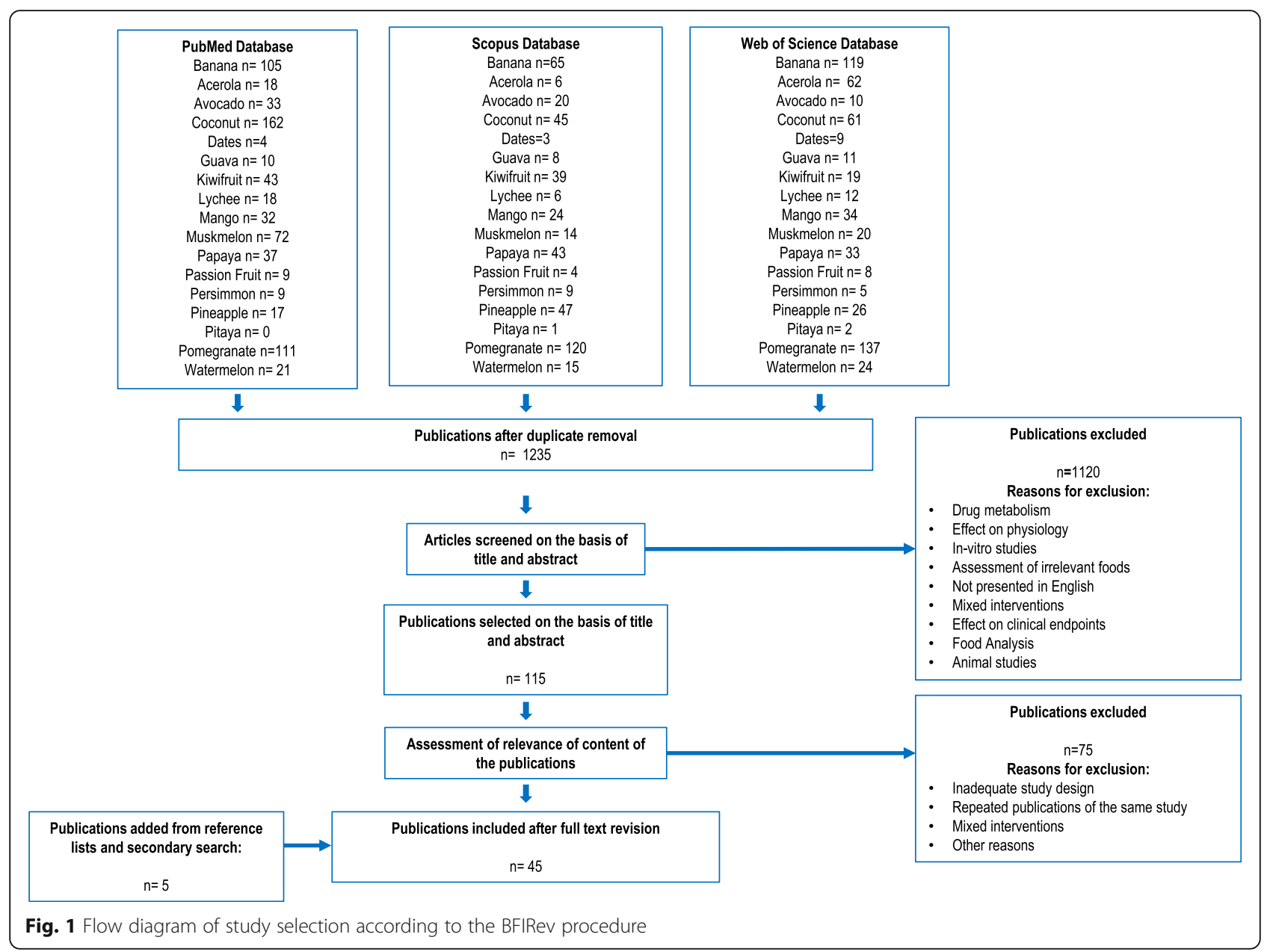

$(30 \pm 7.5 \mu \mathrm{g} / \mathrm{g} \mathrm{FW})$, kiwi fruit $(5.8 \pm 0.9 \mu \mathrm{g} / \mathrm{g} F W)$, plums $(4.7 \pm 0.8 \mu \mathrm{g} / \mathrm{g} \mathrm{FW})$, and tomato $(3.2 \pm 0.6 \mu \mathrm{g} / \mathrm{g} \mathrm{FW})$ [32]. The urinary excretion of HIAA increased by $\sim 2-$ 26-fold after banana intakes ranging from 50 to $1000 \mathrm{~g}$ [32-40, 49], and was comparable to that induced by an oral dose of $10 \mathrm{mg}$ of serotonin [33]. Along with its sulfated conjugate, HIAA was identified as a highly discriminant compound (VIP $>2 ; R^{2}=0.89, Q^{2}=0.732$ ) in a randomized, controlled crossover meal study using untargeted metabolomics to discover BFIs for banana [49]. The important contribution of banana intake to HIAA excretion level was also fortuitously observed in a large study aiming at diagnosing neuroblastoma in Japanese 18-month children. Neuroblastoma is a catecholamine-producing tumor, and an elevated excretion of the dopamine metabolite homovanillic acid was used as a diagnosis biomarker. Among the 103 cases identified with elevated homovanillic acid, 50 were false-positive cases caused by regular intake of banana as weaning food, which was associated with elevated excretion levels of both homovanillic acid and HIAA [37].
While serotonin is not specific to banana, its consumption produces a higher elevation of HIAA in urine compared to other serotonin-rich foods, including tomato, pineapple, and kiwi $[38,39]$. However, nuts intake constitutes a probable confounder for the use of HIAA as BFI for banana. Feldman et al. reported a higher excretion of HIAA after the ingestion of $100 \mathrm{~g}$ of walnuts $(7-59 \mathrm{mg} / 24 \mathrm{~h})$ compared to $100 \mathrm{~g}$ of banana $(4.8-15$ $\mathrm{mg} / 24 \mathrm{~h}$ ) [32]. Recent studies using untargeted metabolomics proposed HIAA in combination with other metabolites as a candidate biomarker for nuts $[58,59]$. Another potential confounder could be fresh tomato, due to its high level of consumption in many populations, but not its processed forms (juices, canned tomato or ketchup) as their serotonin content is much lower $(<$ $0.2 \mu \mathrm{g} / \mathrm{g} F W)$ than in fresh tomato $(6.4 \mu \mathrm{g} / \mathrm{g} F W)$ [60]. The robustness of urinary HIAA is thus not fully established. It was not among the metabolites discriminating low and high consumers of banana from non-consumers in a cross-sectional study with 78 subjects [49]. More studies with non-controlled dietary background and examination of the confounding effect of nuts and 


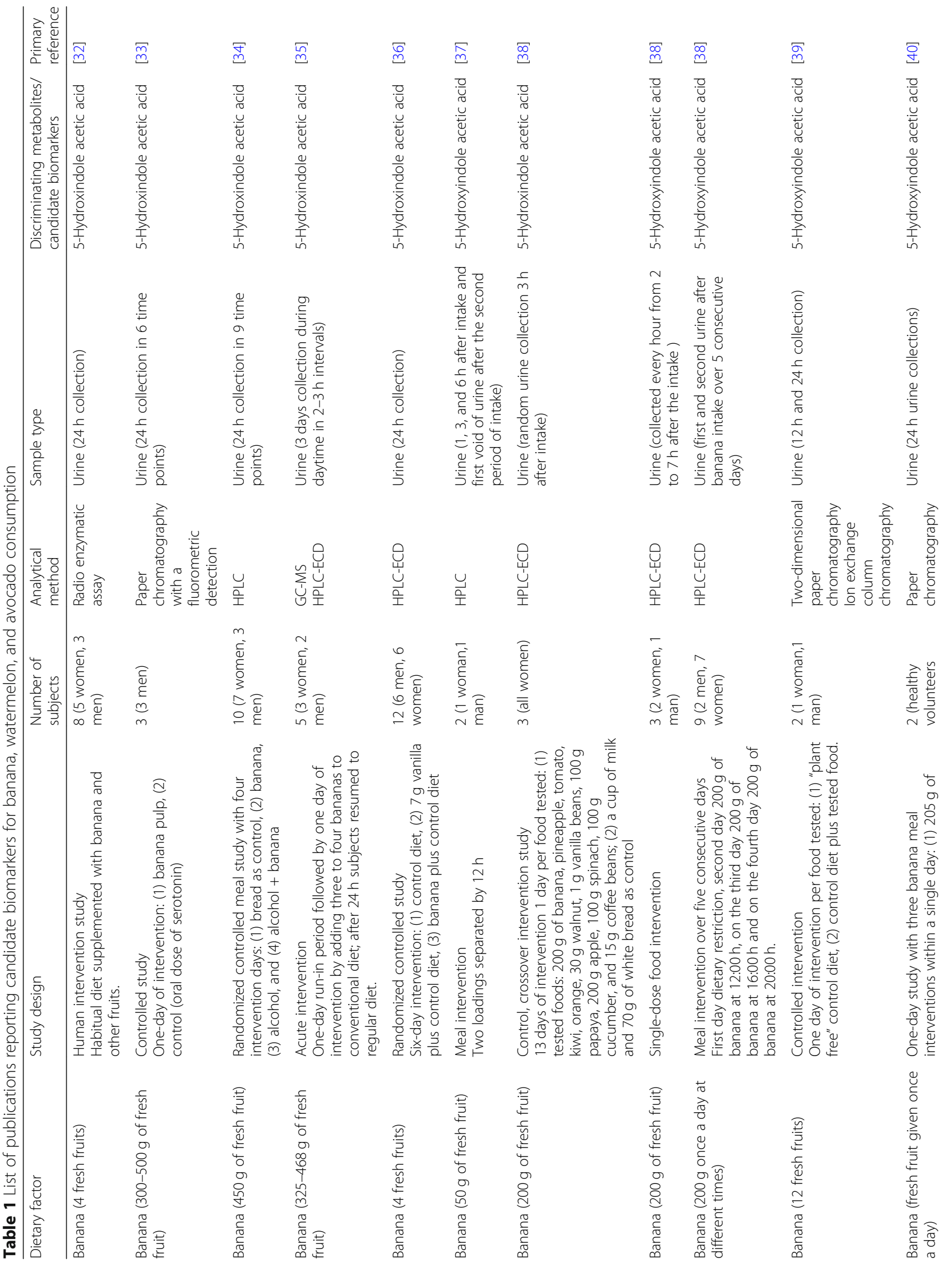




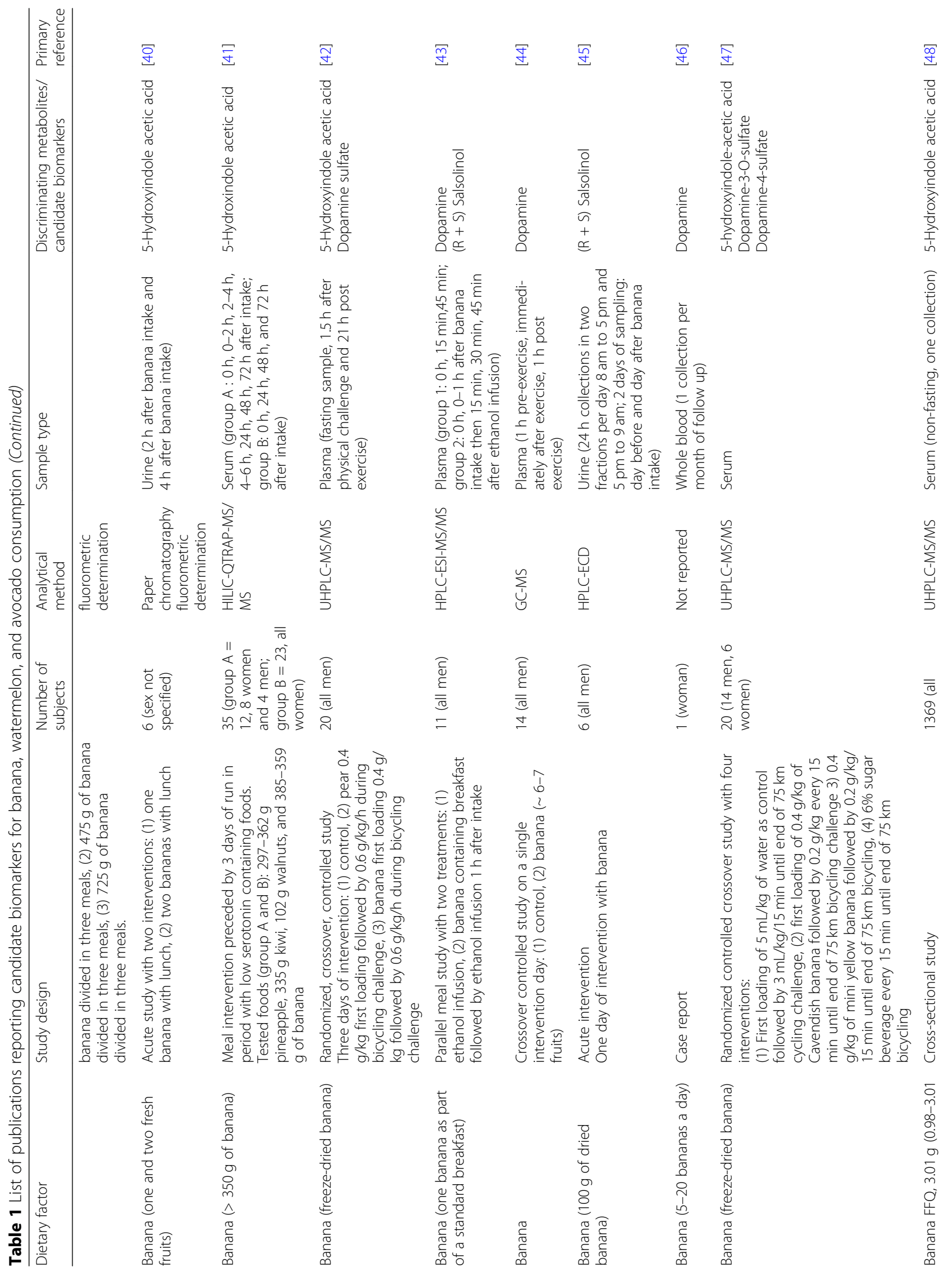




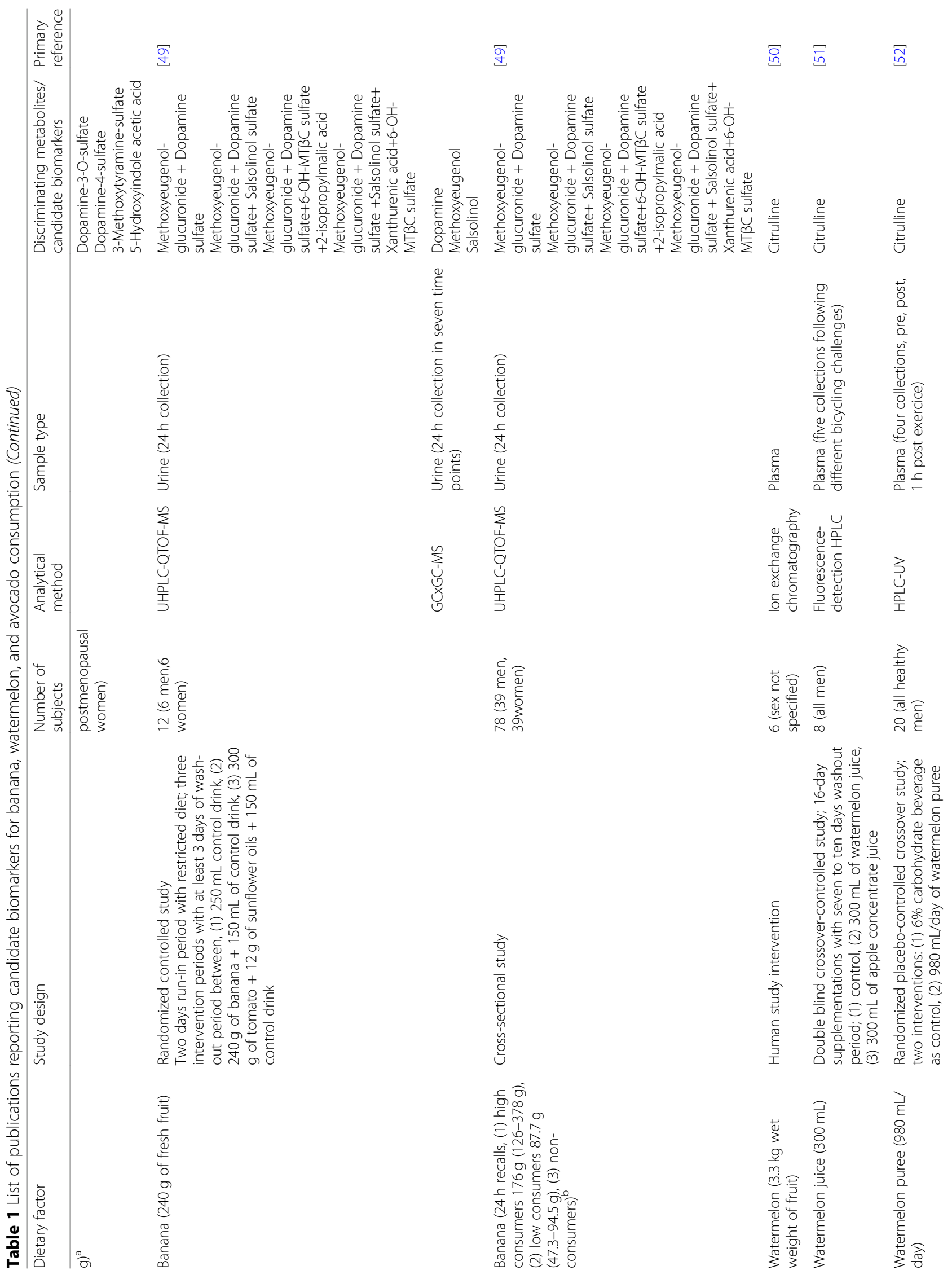




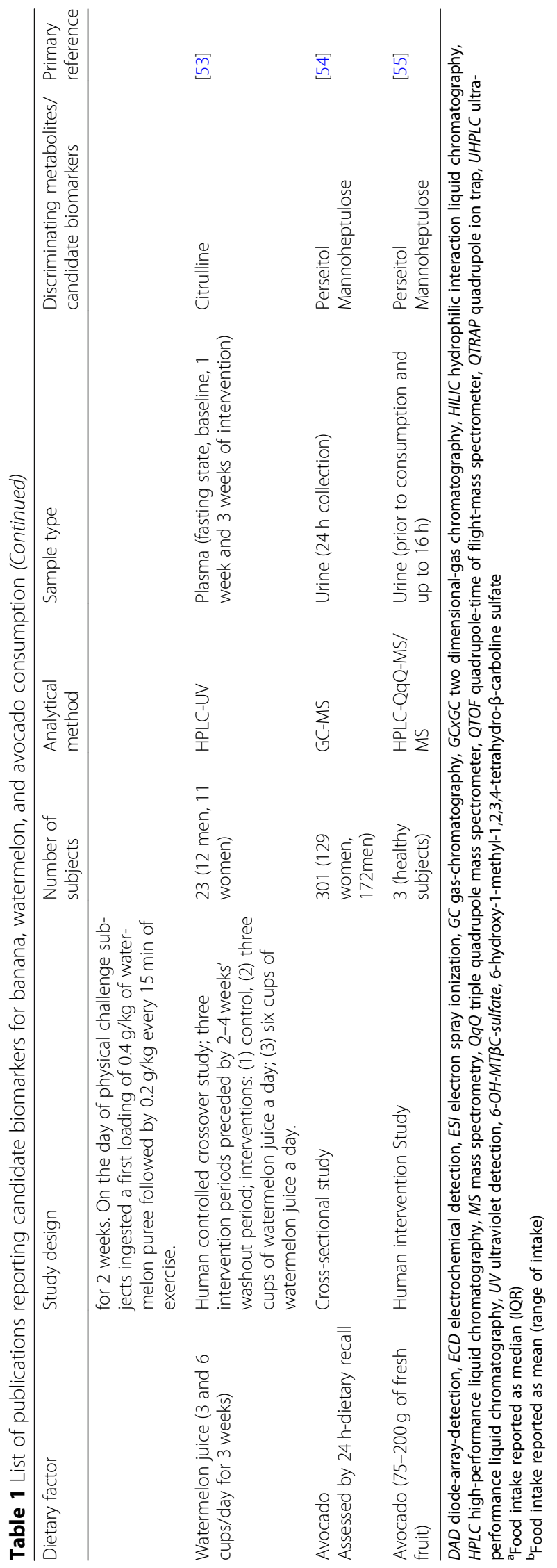




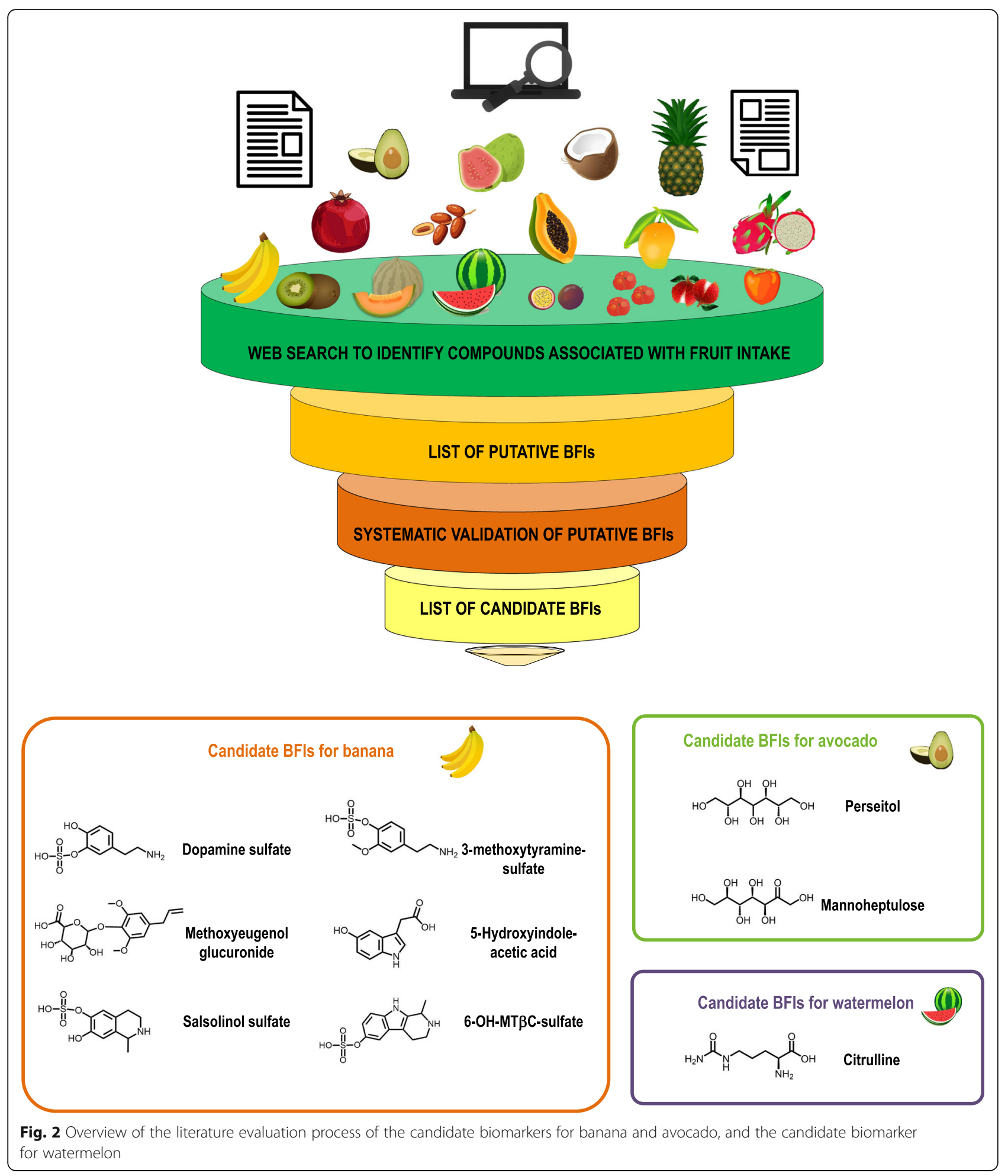

tomato are needed. While no data are available regarding dose-response, the time-response is well documented for HIAA, with a urinary excretion that peaks $2-4 \mathrm{~h}$ after banana intake and returns to baseline levels 8-12 h after consumption [33, 35, 36, 38, 49].
In addition to urine, plasma and serum concentrations of HIAA also increase after banana intake, as reported in four studies [41, 42, 47, 48]. Tohmola et al. measured serum HIAA in response to 35 different foods and showed that walnuts $(102 \mathrm{~g})$ produced the highest 
Table 2 Overview of the validation criteria for candidate intake biomarkers for banana and tropical fruits ${ }^{\mathrm{a}}$

\begin{tabular}{|c|c|c|c|c|c|c|c|c|c|c|c|}
\hline Food item & Metabolites & Biofluid & Q1 & Q2 & Q3a & Q3b & Q4 & Q5 & Q6 & Q7 & Q8 \\
\hline Banana & 5-Hydroxyindole acetic acid & Plasma & Y & $U$ & Y & $u$ & U & U & Y & Y & U \\
\hline Banana & 5-Hydroxyindole acetic acid & Urine & Y & $U$ & Y & $u$ & $u$ & U & Y & Y & $U$ \\
\hline Banana & 3-Methoxytyramine sulfate & Plasma & Y & $U$ & U & U & Y & U & $u$ & U & U \\
\hline Banana & Dopamine sulfate & Plasma & Y & U & Y & $u$ & Y & $u$ & Y & Y & U \\
\hline Banana & Dopamine sulfate & Urine & Y & $Y^{*}$ & Y & $u$ & $U$ & $u$ & Y & Y & $U$ \\
\hline Banana & Methoxyeugenol glucuronide & Urine & Y & $Y^{*}$ & Y & $u$ & $U$ & $u$ & $U$ & $U$ & $U$ \\
\hline Banana & Salsolinol sulfate & Urine & Y & $Y^{*}$ & Y & $u$ & U & $u$ & $u$ & Y & U \\
\hline Banana & 6-OH-MTßC sulfate & Urine & Y & $Y^{*}$ & $U$ & $U$ & $U$ & $U$ & $u$ & $U$ & U \\
\hline Banana & Methoxyeugenol glucuronide + Dopamine sulfate & Urine & Y & $Y^{*}$ & Y & $U$ & Y & Y & $U$ & U & $U$ \\
\hline Banana & Methoxyeugenol-glucuronide + Dopamine sulfate + Salsolinol sulfate & Urine & Y & $Y^{*}$ & Y & $U$ & Y & Y & $U$ & $U$ & $U$ \\
\hline Banana & $\begin{array}{l}\text { Methoxyeugenol glucuronide + Dopamine sulfate }+6-\mathrm{OH}-\mathrm{MT} \beta \mathrm{C} \text { sulfate }+2- \\
\text { isopropylmalic acid }\end{array}$ & Urine & Y & $Y^{*}$ & Y & $u$ & Y & Y & $U$ & U & $U$ \\
\hline Banana & $\begin{array}{l}\text { Methoxyeugenol glucuronide + Dopamine sulfate + Salsolinol sulfate + } \\
\text { Xanthurenic acid + 6-OH-MT } \beta C \text { sulfate }\end{array}$ & Urine & Y & $Y^{*}$ & Y & U & Y & Y & U & U & U \\
\hline Avocado & Perseitol & Urine & Y & $U$ & $Y^{*}$ & U & $U$ & U & U & U & U \\
\hline Avocado & Mannoheptulose & Urine & Y & $U$ & $Y^{*}$ & U & $U$ & U & U & U & U \\
\hline Watermelon & Citrulline & Plasma & Y & $U$ & U & U & $U$ & U & U & U & U \\
\hline Watermelon & Citrulline & Urine & Y & U & U & U & $U$ & U & U & U & $U$ \\
\hline
\end{tabular}

${ }^{\mathrm{a}}$ Questions related to each of the validation criteria: Q1. Is the marker compound plausible as a specific BFI for the food or food group (chemical/biological plausibility)?, Q2. Is there a dose-response relationship at relevant intake levels of the targeted food (quantitative aspect)?, Q3. Is the biomarkers kinetics described adequately to make a wise choice of sample type, frequency and time window (time-response) [a single-meal time-response relationship, b: repeated intakes have]?, Q4. Has the marker been shown to be robust after intake of complex meals reflecting dietary habits of the targeted population (robustness)?, Q5. Has the marker been shown to compare well with other markers or questionnaire data for the same food/food group (reliability)?, Q6. Is the marker chemically and biologically stable during bio specimen collection and storage, making measurements reliable and feasible (stability)?, Q7. Are analytical variability (CV \%), accuracy, sensitivity, and specificity known as adequate for at least one reported analytical method (analytical performance)?, Q8. Has the analysis been successfully reproduced in another laboratory (reproducibility)?

$Y$ yes the criterion is fulfilled, $Y^{*}$ the criterion is partially fulfilled but requires further investigation, $N$ no the principle has not been fulfilled after investigation, $U$ unknown; further data is required to determine the validation of the criterion, $6-\mathrm{OH}-\mathrm{MT} \beta \mathrm{C}$ sulfate 6 -hydroxy-1-methyl-1,2,3,4-tetrahydro- $\beta$-carboline sulfate

elevation of HIAA $(1.8 \mu \mathrm{mol} / \mathrm{L})$, followed by banana $(\sim$ $0.6 \mu \mathrm{mol} / \mathrm{L}$ for $300 \mathrm{~g}$ ingested $)$, pineapple $(0.46 \mu \mathrm{mol} / \mathrm{L}$ for $330 \mathrm{~g})$ and tomato $(0.39 \mu \mathrm{mol} / \mathrm{L}$ for $362 \mathrm{~g})$ [41]. Plasma concentrations of HIAA peaked $2 \mathrm{~h}$ after the intake of all foods and returned to baseline levels $6 \mathrm{~h}$ after the intake of tomato and pineapple and $24 \mathrm{~h}$ after the ingestion of banana and walnuts. The calculated half-life of HIAA in the circulation was of $1.3 \mathrm{~h}$ [41].

Wang et al. conducted a cross-sectional analysis that correlated consumption, using FFQs, of 91 food items or food groups to the non-fasting serum metabolome of 1369 post-menopausal women (Table 1). Herein, HIAA was significantly correlated to banana consumption $(|r|=0.21, P<0.0001)$, although dopamine metabolites showed a better ability to predict banana intake in the same study [48].

Regarding the analytical aspects of the validation scheme for BFIs, quantification of HIAA by HPLC-MS in urine and serum samples is well established [61, 62]. Acidification of urine to a pH between 2 and 5 is recommended for HIAA conservation [63, 64]. At pH 4, HIAA was shown to be stable in urine for up to 30 months at $-20^{\circ} \mathrm{C}$, for 3 months at $4{ }^{\circ} \mathrm{C}$, and for 3 weeks at room temperature [63]. The validation criteria fulfilled so far for HIAA as a biomarker of banana intake are presented in Table 2.

Besides HIAA, the response of dopamine metabolites to banana intake has been widely studied, mostly in plasma and serum [42-44, 46-48], with one publication on urine [49] (Table 1). Banana has a high dopamine content $(73 \pm 24 \mu \mathrm{g} / \mathrm{g})$ [38] compared to other dietary sources such as avocado $(4 \mu \mathrm{g} / \mathrm{g})$, orange, cocoa powder, and tomato $(<1 \mu \mathrm{g} / \mathrm{g})$ [65]. In humans, dopamine is degraded into different metabolites by several pathways [66]. Dopamine-sulfate is the main circulating form originating from both dietary and endogenous dopamine $[67,68]$. 3-Methoxytyramine results from the metabolism of dopamine through its methylation by the enzyme catechol-O-methyl transferase (EC 2.1.1.6) [66]; 3methoxytyramine is further conjugated to its sulfate by the enterocytes or the liver [69].

Dopamine derivatives have been reported as highly distinctive metabolites for banana intake on various occasions. In three intervention studies, banana intake was studied for its effect on the physical endurance of male cyclists, and an untargeted metabolomic analysis of 
serum samples was included. Herein, dopamine, dopamine-3-O-sulfate, dopamine-4-sulfate, and 3methoxytyramine-sulfate were detected in plasma as highly discriminant metabolites for the banana intervention [42, 44, 47]. Other authors examined plasma dopamine responses using targeted methods. In a small pilot study, the addition of one banana to a complex meal significantly increased dopamine levels in plasma $1 \mathrm{~h}$ after intake from $5.8 \mathrm{ng} / \mathrm{mL}$ at baseline to $92.5 \mathrm{ng} / \mathrm{mL}$ [43]. A case report about an anorexic adolescent who consumed $>20$ bananas/day for 26 months mentioned a 20 -fold increase over the normal range of plasma dopamine, which corrected towards normality when the patient resumed the restrictive food ingestion [46]. The latter shows that the intake of banana can increase plasma dopamine to extremely high levels over an extended period of time.

Furthermore, the study by Wang et al. revealed dopamine-3-O-sulfate $(r=0.33, P<0.0001 ;$ AUC $=$ $0.76)$, dopamine-4-sulfate $(r=0.34, P<0.0001 ;$ AUC $=$ $0.74)$, and 3-methoxytyramine sulfate $(r=0.22, P<$ 0.0001 ; AUC $=0.70$ ) as serum metabolites significantly correlated to banana intake with a good ability to distinguish high and low consumers of banana [48]. These observations support the interest of these three metabolites as candidate BFIs for banana intake in plasma as well as in urine. Their level of validation is discussed below and summarized in Table 2.

In urine samples from a randomized controlled, crossover meal study, dopamine sulfate was observed as a highly discriminant metabolite (VIP $>2 ; R^{2}=0.89, Q^{2}=$ 0.732 ) for banana consumption, and seven-fold higher intensity $(P<0.001)$ after the intake of the fruit than control [49]. Additionally, it was observed in higher intensity in the urine of high consumers of banana compared to non-consumers (3-fold higher; $P=6.7 \times 10^{-3}$ ) in a cross-sectional study on a German population, thus supporting its robustness [49]. Dopamine sulfate was a key component of the combinations of metabolites which performed best to predict banana intake, while its performance as a unique biomarker was lower [49].

Regarding the validation criteria, no clear information is available on the dose-response after banana intake for dopamine metabolites in plasma or urine. The timeresponse in plasma showed an elevation $1-2 \mathrm{~h}$ after the intake of banana, persisting up to $8 \mathrm{~h}$ after consumption $[43,70]$ (Table 2). Urinary excretion of dopamine metabolites peaked $2-4 \mathrm{~h}$ after the intake and continued up to $12 \mathrm{~h} \mathrm{[70].} \mathrm{As} \mathrm{for} \mathrm{the} \mathrm{chemical} \mathrm{aspects} \mathrm{of} \mathrm{the} \mathrm{validation,}$ mild acidification of urine samples may be used to avoid catecholamine-oxidation and deconjugation [71]. Sample storage at $-80^{\circ} \mathrm{C}$ should be preferred for catecholamine preservation [72]. Liquid chromatographic methods with different detectors, including mass spectrometry, fluorometric, and electrochemical detection, exist for the determination of dopamine, 3-methoxytyramine and its conjugates in plasma and urine [67, 73, 74]. However, conjugated standards of dopamine or 3-methoxytyramine and other compounds are not commercially available for quantification, which may complicate their use as BFIs.

Another metabolite associated with banana intake is salsolinol. This compound is synthesized in banana by the condensation of dopamine and acetaldehyde (PictetSpengler reaction) [75]. It is also an endogenous metabolite [76]. Salsolinol concentration in banana pulp is of $6.3 \times$ $10^{-2} \mu \mathrm{g} / \mathrm{g}$ and it is present at lower concentration in other sources including beer $\left(0.5 \times 10^{-2}\right.$ to $\left.1.3 \times 10^{-2} \mu \mathrm{g} / \mathrm{g}\right)$ and French wine $\left(3.3 \times 10^{-3}\right.$ to $\left.4.9 \times 10^{-3} \mu \mathrm{g} / \mathrm{g}\right)$ [77-79]. Salsolinol is also highly present in cocoa powder $(25 \mu \mathrm{g} / \mathrm{g})$ and chocolate $(19 \mu \mathrm{g} / \mathrm{g})$ [80]. There are two existing isomers of salsolinol, the $(\mathrm{R})$ isomer that is proposed to be mainly of endogenous origin and the $(S)$ enantiomer that may be more susceptible to diet. Strolin-Benedetti et al. reported that in $24 \mathrm{~h}$ urine samples of 6 subjects before consumption of banana, the concentration of (S)-salsolinol was close to zero and increased after the intake of dried banana. In contrast, the $(\mathrm{R})$ isomer increased after the intake of the fruit but was already present prior consumption [45]. Lee et al. studied the influence of banana intake on blood concentration of salsolinol in healthy subjects. They showed that after the intake of one banana fruit, the concentration of salsolinol increased from $0.16 \pm 0.12$ to $5.8 \pm 7.6 \mathrm{ng} / \mathrm{mL}$ and from $0.23 \pm 0.16$ to $6.6 \pm 8.7 \mathrm{ng} / \mathrm{mL}$, for the (S)- and (R)-forms, respectively, $1.5 \mathrm{~h}$ postconsumption [43]. This shows that the consumption of banana causes a detectable increase of salsolinol in plasma. The kinetics of this compound was studied only in rats, after gavage with $10 \mu \mathrm{g}$ of salsolinol and $3 \mathrm{~g}$ of banana. In both interventions, salsolinol increased in plasma $1 \mathrm{~h}$ after intake and cleared $14 \mathrm{~h}$ post consumption [43].

Salsolinol sulfate was observed as the most distinctive urinary metabolite with a 46-fold higher intensity after a single dose of banana compared to a control meal in 12 healthy subjects (VIP > 2; $R^{2}=0.89, Q^{2}=0.732 ; P<$ 0.001) [49]. In the KarMeN cross-sectional study, this metabolite was also detected in higher intensity in the urine samples of high-consumers compared to nonconsumers (10-fold higher in high consumers, $P=2 \times$ $10^{-2}$ ). However, further analysis showed that salsolinol sulfate alone was not specific enough to predict consumers and non-consumers of banana in this population (misclassification rate $>30 \%$ ). The robustness of plasma and urine salsolinol as a biomarker of banana intake is possibly challenged by the intake of chocolate, and/or alcohol as their consumption was shown to markedly elevate the levels of salsolinol in biofluids [81]. Intervention studies comparing the response of salsolinol or its conjugates to the intake of different salsolinol-containing 
foods are needed to further clarify the potential use of salsolinol as a candidate BFI for banana, possibly as a component of a multi-marker.

Among the assessed studies, the one by Vázquez-Manjarrez et al. was specially designed for the discovery and validation of banana biomarkers. Herein, urine samples from two different study designs were analyzed, a controlled, cross-over meal study with $240 \mathrm{~g}$ of banana ( $n=$ $12)$ and a cross-sectional study (KarMeN) $(n=78)$ with high (126-378 g of banana), low (47.3-94.5 g of banana), and non-consumers of banana using an untargeted multi-platform metabolomics approach [49]. Thirtythree banana-derived metabolites were identified in urine in the meal study, including HIAA, dopamine, and salsolinol metabolites, which have been discussed above, and other highly distinctive metabolites such as methoxyeugenol glucuronide (VIP $>2, R^{2}=0.89, Q^{2}=0.732$; 26-fold higher in banana than control, $P=1.3 \times 10^{-10}$ ), 2-isopropylmalic acid (VIP $>2, R^{2}=0.89, Q^{2}=0.732$; 9fold higher in banana than control $P=1.4 \times 10^{-7}$ ), Nacetyldopamine sulfate (VIP $>2, R^{2}=0.89, Q^{2}=0.732$; 4-fold higher in banana than control $P=1.1 \times 10^{-6}$ ), 6hydroxy-1-methyl-1,2,3,4-tetrahydro- $\beta$-carboline sulfate (6-OH-MT $\beta$ C sulfate) (VIP $>2, R^{2}=0.89, Q^{2}=0.732$; 4-fold higher in banana than control, $P=2.3 \times 10^{-2}$ ). The cross-sectional KarMeN study showed that methoxyeugenol glucuronide $\left(P=4.70 \times 10^{-5}\right)$, dopamine sulfate $\left(P=6.7 \times 10^{-3}\right)$, salsolinol sulfate $\left(P=2 \times 10^{-2}\right)$, 6OH-MT $\beta C$ sulfate $\left(P=3.6 \times 10^{-2}\right)$, and xanthurenic acid $\left(P=6.7 \times 10^{-3}\right)$ had significant higher intensities, ranging from 6 - to 25 -fold change, in the urine of highconsumers of banana compared to non-consumers, while only methoxyeugenol glucuronide was significantly higher ( 15 -fold, $P=5.20 \times 10^{-5}$ ) in low-consumers compared to non-consumers [49]. None of the putative biomarkers was robust enough when used alone, but the authors demonstrated that dopamine sulfate and methoxyeugenol glucuronide was the best parsimonious combination to detect the intake of banana in high consumers (AUC $=0.92$, ER $=0.11$ ) and low consumers (AUC $=0.87, \mathrm{ER}=0.19)$ [49]. The origin of methoxyeugenol glucuronide was attributed to the metabolism of the characteristic banana aroma methoxyeugenol and elemicin [82]. Methoxyeugenol and elemicin were also reported in nutmeg and star anise [82, 83], respectively, which represent marginal confounders. Regarding doseresponse, the intensity of the combined BFIs showed a linear trend with the amount of banana consumed in the intervention study and that reported in $24 \mathrm{~h}$ recalls by the high and low consumers in the cross-sectional study. However, quantitative studies are required to fully validate the proposed combined BFI in this critical aspect (Table 2). The metabolite 6-OH-MT $\beta \mathrm{C}$ sulfate was also frequently present in the best combinations of biomarkers reflecting high banana intake in the KarMeN study. The 6-OH-MT $\beta \mathrm{C}$ derives from the condensation of serotonin with acetaldehyde and is present in banana in higher concentrations $(1.87 \mathrm{mg} / \mathrm{kg})$ than in other fruits, including tomato $(0.71 \mathrm{mg} / \mathrm{kg})$, kiwi $(0.31 \mathrm{mg} / \mathrm{kg})$, and pineapple $(0.62 \mathrm{mg} / \mathrm{kg})$ [84]. Dark chocolate contains higher levels of 6-OH-MTßC $(2.64 \mathrm{mg} / \mathrm{kg})$ [85] than banana and thus would constitute a potential confounder.

Melatonin metabolites have been associated with banana consumption in other selected publications. While melatonin is produced endogenously in the pineal gland, the intake of melatonin-rich foods such as banana, pineapple, cherries, and orange substantially elevate the concentration of melatonin and 6-sulfatoxymelatonin, its main metabolite, in urine and serum $[86,87]$. Other dietary sources of melatonin are walnuts, mango, papaya, grapes, wine, and olive oil. The use of melatonin and its main metabolite as a candidate BFI for banana or any other fruit is also hindered by its fluctuation during the daytime [88] and by the fact that melatonin is sold overthe-counter in different countries as a supplement to adjust sleeping disorders.

Many other metabolites have been identified in biofluids after the intake of banana but have less relevance as candidate BFIs (Table S2). 3,4-Dihydroxyphenyl-acetic acid, homovanillic acid, 3-hydroxytyrosol, and 5,6-dihydroxyindole were observed as part of the "dopamine signature" of banana [36, 38, 49]. However, 3,4-dihydroxyphenyl acetic acid and homovanillic acid originate from the microbial metabolism of polyphenols, which are widely distributed in plant-based foods $[89,90]$. 3-Hydroxytyrosol in urine may better reflect olive-oil consumption [59]. Plasma 2,3dihydroxy-isovalerate, 4-guanidinobutanoate, ferulic acid 4-sulfate, and 4-acetylphenol sulfate were associated with banana intake in controlled intervention studies with banana [42, 47]. However, 2,3-dihydroxy-isovalerate is an intermediate in the biosynthesis of valine, leucine, and isoleucine while 4-guanidinobutanoate participates in the metabolic pathway of arginine. Ferulic-acid-4 sulfate is a metabolite of ferulic acid and caffeic acid, which are widely distributed in fruits, cereals, and coffee [28, 30]. 4Acetylphenol has been detected in different medicinal herbs and is a flavoring and aroma ingredient in roasted coffee, beer, mango, and cranberry [21]. Interestingly 2isopropylmalic acid, eugenol sulfate, and fructose were observed by different groups after banana intake [42, 47, 49]. Fructose is a common carbohydrate present in a wide range of foods, which excludes its use as a BFI of banana. 2-Isopropylmalic acid has been identified as a key compound for organoleptic characteristics of melon [91] and is present in other vegetables and fruits including lettuce and tomato juice $[92,93]$. The fact that this metabolite was recovered in biofluids following consumption of 
different vegetal sources including pear, banana, and peas $[42,47,49,94]$ suggests its possible utility as putative BFI for the general intake of this food group. Eugenol sulfate results from the phase II metabolism of the aroma compound eugenol which is present in banana and other highly consumed fruits such as apple, apricot, and cherry as well as spices including black pepper and clove [21]. The microbiota metabolites of tryptophan, indolepropionate, and indoleacetate have been associated with the intake of banana $[47,95]$ but also with the consumption of other fruits including apple and pear [95]. Xanthurenic acid, which was found to be increased in urine after banana intake [49], originates from the kynurenine pathway of tryptophan degradation [96]. Whereas banana has a higher content $(10 \mathrm{mg} / 100 \mathrm{~g})$ of tryptophan than other fruits (e.g., apple $3 \mathrm{mg} / 100 \mathrm{~g}$ ) [97], other dietary sources very rich in tryptophan, e.g., cheese and fermented products would act as strong confounders [98].

Late urinary excretion of al N-methyl-2-pyridione-5carboxylic acid, likely a microbial metabolite of trigonelline, was observed by Vázquez-Manjarrez et al. [49], but the presence of trigonelline in coffee excludes its use as BFI for banana. Metabolites from carboxylic acids, saccharides, and amino acids were also reported in the urine. Among them, sinapic acid-sulfate, hydrocinnamic acid sulfate, vanillic acid, mevalonic acid, azelaic acid, 1 , 5 anhydrosorbitol, fructose, glyceraldehyde, and 2-ethyl3-hydroxyl propionic acid were found to be increased in urine samples in studies within a controlled setting but not under free-living conditions [49].

In conclusion, we have identified several candidate BFIs for banana intake including metabolites of catecholamines, indolamines, and specific aroma compounds (Fig. 2). While these metabolites are candidate BFIs for banana, they are challenged when considered individually by their endogenous presence in the human body or in other foods. However, the combined use of several candidate BFIs, namely dopamine sulfate, salsolinol sulfate, 6-OH-MT $\beta \mathrm{C}$ sulfate, and methoxyeugenol glucuronide in urine and HIAA along with 3-methoxytyramine sulfate in plasma, offers a more robust alternative to determine exposure to banana in free-living conditions. These candidate biomarkers can reflect banana intake qualitatively (absence/presence of consumption) but dose-response studies must be conducted to push them forward as quantitative BFIs.

\section{Papaya and watermelon biomarkers}

Much less information has been found on candidate BFIs for tropical fruits other than banana. Some carotenoids have been proposed as biomarkers of tropical fruit intake. In particular, lycopene, $\beta$-carotene and $\beta$ cryptoxanthin have been associated with papaya and watermelon intake, while lutein and $\beta$-carotene have been associated with intake of papaya and mango [99101]. Tropical fruits have been studied as sources of pro-vitamin A carotenoids for many developing countries with a high occurrence of vitamin A deficiency, and the literature reflects this interest. Carotenes are present in too many foods to be envisaged as biomarkers for specific tropical fruits. $\beta$-Cryptoxanthin was shown to increase in plasma after acute intake of papaya [102] and has also been correlated with habitual intake of tropical fruits in a study with 159 Costa-Rican adolescents [101]. Papaya was the best food predictor of plasma $\beta$ cryptoxanthin in this study. Yet, although papaya is indeed one of the richest sources of $\beta$-cryptoxanthin, this compound can also originate from other orange- or redcolored foods such as orange, mango, apricot, sweet peppers, and pumpkin, as well as from spices and herbs including paprika, dill, and basil $[30,103]$. In the Nurse's Health study conducted in a US population with low consumption of papaya, orange juice was actually reported to be the major determinant of plasma $\beta$ cryptoxanthin [104].

Watermelon, and to a lesser extent papaya, contains a substantial amount of lycopene in a highly bioavailable form [102]. Watermelon has a lycopene content ranging from 4.8 to $13.5 \mathrm{mg} / 100 \mathrm{~g}$ fresh weight representing a content equivalent to that measured in most tomato cultivars [103]. However, processed forms of tomato such as tomato sauce are even more concentrated. Considering the higher consumption of tomato products compared to watermelon in most populations, blood concentration of lycopene is more likely to reflect the intake of tomato and derived products than that of watermelon.

Although the common dietary carotenoids lack specificity for tropical fruit intake, it cannot be ruled out that less studied carotenoids among the dozens identified in tropical fruits, for example, cryptoxanthin-5,8-epoxide or sapotexanthin may arise as more specific candidate biomarkers in future metabolomic studies [105].

Aside from carotenoids, the literature search revealed citrulline as a possible biomarker of watermelon intake. Interestingly, the name of this amino acid was derived from the latin name of watermelon, Citrullus vulgaris, from which it was first isolated. A case study reported a ten times elevation of citrulline plasma concentration in a young girl who was consuming large quantities of watermelon, and this was confirmed in a dietary intervention on six healthy adult volunteers [50]. Plasma citrulline peaked $1 \mathrm{~h}$ after watermelon intake $(593 \mu \mathrm{M})$, was still elevated at $8 \mathrm{~h}$ and returned to the normal range $(20-40 \mu \mathrm{M})$ at $24 \mathrm{~h}$. Other authors have observed L-citrulline responses in plasma following watermelon intake. A 16-day supplementation with $300 \mathrm{~mL} /$ day of a watermelon concentrated juice providing $3.4 \mathrm{~g}$ of citrulline/day resulted in 3.5-4.6 fold higher plasma 
concentrations of citrulline compared to control or apple juice interventions [51]. A transitory increase in plasma L-citrulline occurred for 20 subjects who consumed 0.2 $\mathrm{g} / \mathrm{kg}$ of watermelon puree every 15 min during a physical challenge, with a return to baseline levels $3-5 \mathrm{~h}$ after the end of the supplementation [52]. Collins et al. did not observe any significant change in L-citrulline plasma concentration following the ingestion of watermelon juice, up to 6 cups/day for 3 weeks [53]. However, measurements were made on $12 \mathrm{~h}$ fasting plasma samples, which concurs with the short-term responses observed by other authors. Citrulline also has an endogenous origin, synthetized from glutamine or arginine in the enterocytes [106]. It is a key intermediate of the urea cycle in the liver and is readily converted to arginine and then nitric oxide in the kidney and vascular endothelium. Citrulline plasma concentration reflects the equilibrium between its synthesis in the intestine and its conversion to arginine in the kidney. Low or high citrulline status has been proposed as a biomarker of intestinal dysfunction in various intestinal pathologies as well as markers of acute kidney failure and of some inborn errors of the urea cycle [106]. It is worth noting that after watermelon intake plasma arginine was also modestly elevated, whereas venous ammonia, plasma glutamine, and other amino acids remained in the normal range, which does not correspond to the metabolic patterns classically observed with urea cycle, renal or intestinal disorders.

In conclusion, the concentration of citrulline in plasma and possibly in urine could be further explored as candidate biomarker for assessing watermelon intake in healthy individuals (Fig. 2). Regarding papaya, there are no putative BFIs reported in the literature yet. To further discover candidate BFIs for both fruits, controlled intervention trials with different doses of the fruits and applying an untargeted metabolomics approach may be performed.

\section{Avocado biomarkers}

Avocado (Persea Americana) is unique in its low content in starch and sugars and high content in monounsaturated fatty acids 71\% [107]. Using a semi-targeted GCxGC-MS sugar profiling method, Mack et al. analyzed $24 \mathrm{~h}$ urine samples of 301 volunteers of the KarMeN cross-sectional study to search associations between excreted sugar metabolites and the dietary information obtained with 24dietary recalls [54]. From the Spearman rank correlation analyses with the entire population, two seven-carbon carbohydrates, perseitol $(\rho=0.33, p$ values $<0.0001)$ and mannoheptulose $(\rho=0.2702, p$ values $<0.0001)$ were significantly associated with avocado intake. Further correlation analyses including only avocado consumers $(n=9)$ and non-consumers $(n=18)$ confirmed the strong association of perseitol $\rho=0.871$ and mannoheptulose $\rho=0.778$ with avocado consumption [54].
The authors analyzed perseitol and mannoheptulose in 75 foodstuffs to determine their plausibility and specificity as candidate BFIs for avocado. Perseitol was only observed in avocado while mannoheptulose was more concentrated in avocado than in the other fruits and vegetables where it was detected (carrot, blueberry, fig, and tomato) [54].

Wamelink et al. have developed a HPLC-QqQ-MS/MS method of analysis for the seven-carbon carbohydrates and validated it with a small human intervention on 3 subjects consuming avocado (75-200 g) [55]. Urine excretion of perseitol and mannoheptulose but not of other seven-carbon carbohydrates were elevated between 3 and $12 \mathrm{~h}$ after avocado intake. A high interindividual variation was observed that may be due to a different content of C7 carbohydrates in avocados. Of note, in subjects with transaldolase deficiency, a recently discovered pentose phosphate pathway alteration, a subtle elevation of mannoheptulose and perseitol in urine can be observed along with other $\mathrm{C} 7$ carbohydrates and polyols [55]. This will deserve further attention to determine whether intrinsic factors can affect the excretion of the candidate biomarkers and jeopardize their use.

In conclusion, the limited data available suggest that perseitol and mannoheptulose may be considered as short-term candidate BFIs for avocado. They have been validated for plausibility, and partially for robustness and time-response (Table 2, Fig. 2). However, human studies with larger sample sizes are needed to further validate these candidate BFIs and assess dose-response, reliability, and performance of their quantification method(s).

\section{Date biomarkers}

Date fruit is a highly nutritious fruit that contains about $70 \%$ of carbohydrates, as well as dietary fibers and a wide range of micronutrients and secondary metabolites [108, 109]. The first and only study that aimed to identify metabolic changes occurring in blood after consumption of date fruit was conducted by Mathew et al. [110]. They applied an untargeted metabolomics approach based on LCMS on blood samples from 21 subjects who underwent three dietary interventions: (1) a control glucose drink, (2) ten date fruits of the Deglet Nour variety, and (3) ten date fruits of the Khlas variety. A total of 28 molecules were found to significantly increase (Bonferroni corrected $p$ value $<0.05)$ over $2 \mathrm{~h}$ after the date fruit challenges, among which 20 were identified. Several phenolic acid metabolites were found to be discriminant, including ferulic acid 4-sulfate, caffeic acid-sulfate, 4-vinylguaiacol sulfate, and vanillic alcohol sulfate. This was consistent with the presence of 3,4,5-trimethoxycinnamate, 3,4-dimethoxycinammic acid, 4-hydroxycinnamate, dihydroferulic acid, ferulic acid, and isoferulic acid in the date fruit. However, those phenolic metabolites can derive from many fruits 
and vegetables and are therefore of little interest as candidate biomarkers for date fruit. In the same study, 2isopropylmalic acid was observed as a distinctive metabolite for recent date intake. As already mentioned, this compound is also recovered in biofluids after intake of peas or different fruits including banana, tomato, and pear [42, 49, 93, 94]. Some carboxyethylated amino acids were detected in plasma after the intake of both varieties of dates, including 1-carboxyethylisoleucine, 1-carboxyethylleucine, 1carboxyethyltyrosine, and 1-carboxyethylvaline. These compounds, considered to be advanced glycation products, are formed by non-enzymatic reactions between reducing sugars and proteins [111, 112]. They are most likely formed in the dates during drying, but they might also be formed endogenously after intake of dates as a consequence of their high content of fructose [112].

Based the scarce information available on human metabolites observed after intake of date fruit, it is not yet possible to identify a candidate BFI. Some more specific caffeoylshikimic acids, e.g., dactylifric acid (3-O-caffeoylshikimic acid), neodactylifric acid (5-O-caffeoylshikimic acid), and isodactylifric acid (4- O-caffeoylshikimic acid) resulting from enzymatic browning of date fruit [29, 113] and xanthoxylin [114] may be of interest as putative biomarkers but their metabolic fate in humans remain to be elucidated.

\section{Pomegranate biomarkers}

Pomegranate is mainly consumed fresh or in the form of juice. It is characterized by its content of rare ellagitannins, including punicalin and punicalagin $\mathrm{A}$ and $\mathrm{B}$. Thus, it comes as no surprise that most of the retrieved literature focused on urolithins. Urolithins are dibenzo- $[b, d]$ pyran-6-one derivatives produced from ellagic acid and ellagitannins by the gut microbiota $[115,116]$ and to which various beneficial effects on human health have been attributed [117, 118].

After consumption of pomegranate, urolithins appear in plasma $6-8 \mathrm{~h}$ after exposure and persist in plasma and urine up to $48-72 \mathrm{~h}[116,119-125]$ (Table S2). It is likely that the primary precursor of urolithins from pomegranate is punicalagin, which constitutes the major ellagitannin present in this fruit.

Two main factors limit the usefulness of urolithins as BFIs for pomegranate. Firstly, their precursors, namely ellagitannins and ellagic acid, are distributed in other highly consumed foods, including berries and walnuts. The estimated dietary contribution of total ellagitannins as assessed by 3-day dietary records and chromatographic analysis revealed five primary dietary sources of ellagitannins: strawberries, blackberries, walnuts, pomegranate juice, and preserved foods [123]. Of these foods, berries accounted for almost half (42\%) of the estimated intake of ellagitannins, followed by pomegranate
(27.6\%), walnuts $(26.7 \%)$, and strawberry jam (4.1\%). Tea infusions (Camelia Sinensis) also contain ellagitannins and ellagic acid [126]. The high frequency of consumption of tea, berries, and walnuts makes them potential confounders for the use of urolithins as BFIs for pomegranate. The second limiting factor is the high interindividual variation in the production of urolithins caused by variable gut microbiota functionality [127]. From the analysis of urine samples of subjects involved in different dietary interventions with walnuts, pomegranate, or berries, the group of Tomás-Barberan and others reported the occurrence of three ellagitanninmetabolizing phenotypes: metabotype $\mathrm{A}$, metabotype $\mathrm{B}$, and metabotype 0 [115-117, 124, 127-131]. Metabotype A subjects, representing $25-80 \%$ of the tested populations, produce solely urolithin A conjugates. Metabotype $B$ found in $10-50 \%$ of the volunteers produce isourolithin A and urolithin B besides urolithin A. Lastly, subjects with metabotype 0 , less than $10 \%$ of the population, do not produce any of these urolithins.

In conclusion, urolithins are not promising candidate BFIs for pomegranate and additional work has to be done to identify specific BFIs that would apply for all subjects regardless of their metabotype. As no other specific pomegranate component has been highlighted so far, the best approach to identify putative BFIs for pomegranate is to conduct an explorative intervention study with untargeted metabolomic profiling of the collected biofluids and later validate the robustness of the discovered candidates in a population in free-living conditions.

\section{Mango biomarkers}

Mango is a rich source of phytochemicals including diverse polyphenols such as catechins, quercetin, kaempferol, rhamnetin, anthocyanins, gallic acid, ellagic acid, protocatechuic acid, and benzoic acid, which are all widely distributed in other fruits [132, 133]. Gallic acid has been found as the most abundant in mango pulp [134] along with different polymers of the same metabolite in the form of gallotannins. Barnes et al. studied the bioavailability of galloyl derivatives after consumption of mango (Keitt variety). Eleven healthy volunteers underwent a dietary intervention with $400 \mathrm{~g}$ of mango daily for 10 days. Plasma and urine samples were collected on the first and last days of intervention. While no response was observed in plasma, seven metabolites of gallic acid and pyrogallol derivatives were detected in urine [134]. The gallic acid metabolites 4-methylgallic acid and 4-O-methylgallic acid-3-O-sulfate accounted for $43-54 \%$ of the total administered gallic acid and showed a rapid urinary excretion peaking at $6 \mathrm{~h}$ and returning to baseline $8-12 \mathrm{~h}$ after the intake of mango [134]. The other five metabolites were pyrogallol conjugates that originate from the microbial decarboxylation 
of gallic acid, namely isoforms of $O$-methylpyrogallol- $O$ sulfate, pyrogallol-O-sulfate, and deoxypyrogallol-O-sulfate [135]. These five metabolites had a urinary excretion peaking at $12 \mathrm{~h}$ after the consumption of mango. After 10 days with $400 \mathrm{~g} /$ day of mango, pyrogallol- $O$-sulfate and deoxypyrogallol-O-sulfate were the most prevalent metabolites with a significantly increased urinary excretion $(>60 \%, P<0.05)$.

Quirós-Sauceda et al. reported consistent results on pyrogallol metabolites in hydrolyzed plasma and urine samples of 12 male volunteers after the intake of a different variety of mango (Ataulfo) [133]. Five compounds, i.e., gallic acid, chlorogenic acid, protocatechuic acid, ferulic acid, and genistic acid, all unspecific for mango intake, were detected in hydrolyzed plasma $2-4 \mathrm{~h}$ after the intake of either $500 \mathrm{~g}$ of mango pulp or $721 \mathrm{~g}$ of mango juice. In urine, gallic acid, pyrogallol, chlorogenic acid, vanillic acid, p-coumaric acid, ferulic acid, and sinapic acid were detected [133]. Most metabolites showed a rapid urinary excretion while pyrogallol was observed over 8-24h after the intake of mango in both forms.

None of the aforementioned phenolic metabolites may be considered as candidate BFIs for mango due their low specificity for this fruit. Pyrogallol and its conjugates have been detected in human biofluids following the intake of other fruit products, such as grape juice and berries [136, 137]. Mangiferin, a xanthonoid, has been isolated from the pulp of different mango varieties including the Keitt and Ataulfo used in the studies discussed in this section [132]. While its presence and specificity for mango makes it plausible candidate BFI for mango, no information is available yet on the bioavailability of this compound. Its combination with metabolites of pyrogallol may be further tested as a candidate multi-marker for mango.

\section{Potential biomarkers for other tropical fruits}

In spite of the frequent consumption of kiwi, muskmelon, pineapple, guava, and persimmon, there is a remarkable paucity of information on their metabolites in human studies, and even fewer data are available for the less common tropical fruits acerola, litchi, pitaya (dragon fruit), and coconut.

Abdul et al. examined the metabolic profiling of three varieties of kiwi including the most consumed Hayward cultivar (Actinidia deliciosa), the mini kiwi (Actindia arguta), and the less known Bidan (Actinidia eriantha) [138]. Only non-specific compounds were detected, including phenylalanine, tyrosine, arginine, citric acid, glutamine-hydroxy-L-proline, 4-aminobutyrate (GABA), glutamate, glutamine, quinic acid, actinic acid, shikimate, mannose, syringic acid, and afzelechin [22, 138].

Muskmelon, or cantaloupe, is a widely consumed fruit in different countries. Besides their content in $\beta$ - cryptoxanthins, other interesting phytochemicals reported in this fruit are cucurbitin and cucurbitacin $\mathrm{E}$ and B $[21,22,139]$ (Figure S1). Little is known about the bioavailability of these compounds after consumption of muskmelon, and they have also been reported in other fruits of the cucurbitacae family, such as cucumber or pumpkin [22, 24]

Regarding guava, while no publications were retrieved that report specific metabolites following its intake, some specific terpenes have been described in the fruit. Qin et al. reported the presence of guadial, guajadial, 4, 5-diepipsidial, psiguadial, and two novel meroterpenoids, psiguajavadial A and B [140]. Although studies on the bioavailability and pharmacokinetics of terpenes in humans are scarce, evidence indicating their bioavailability after the intake of other fruits exists [141, 142]. Thus, these metabolites might constitute putative biomarkers for the intake of guava (Figure S1). Moreover, the presence of mongolicain-A, an ellagitannin, has been reported solely in guava $[22,29]$ advocating for a potential role as a putative BFI for this fruit. However, as discussed previously its bioavailability in humans in not documented and it may be metabolized into nonspecific compounds like urolithins with a high interindividual variation.

Pineapple belongs to the Ananas cosmosus species. Like in other tropical fruits, melatonin is present in pineapple and its consumption has been shown to produce an elevation of 6-sulfatoxymelatonin in urine of healthy adults [143]. However, as discussed in the "Banana biomarkers" section this metabolite is not relevant as a BFI for either pineapple or any other fruit due to its natural abundance in many fruits and in supplements. Ananasic acid, a specific triterpenoid reported in pineapple [21, 22, 144], may be further studied for its plausibility as a putative BFI for pineapple.

Leucodelphinidin-3-glucoside [145], kakidiol, and methyl-phaeophorbide A and B are listed in different food databases for persimmon [21-23] (Figure S1). Information on the bioavailability of these compounds after human consumption of persimmon is not available. Finally, no specific phytochemicals were identified for litchi, pitaya (dragon fruit), coconut, or acerola in our review process.

\section{Conclusion}

In spite of the important presence of tropical fruits in the human diet, there has been very little interest so far for biomarkers of their intake, and except for banana, no studies have been specifically designed for identifying such biomarkers. For banana consumption, dopamine sulfate, salsolinol sulfate, 6-OH-MT $\beta \mathrm{C}$ sulfate, methoxyeugenolglucuronide, HIAA, and 3-methoxytyramine sulfate are candidate biomarkers. The combination of some of these 
individual compounds may strengthen their robustness to overcome the exposure to potential confounders, as demonstrated for the combination of methoxyeugenol glucuronide and dopamine sulfate in the urine. However, doseresponse studies are needed to validate the latter combination as an accurate quantitative BFI for banana. Citrulline is a candidate BFI for watermelon but its robustness, especially given its endogenous formation in the gut epithelium, has to be assessed in population studies. Perseitol and mannoheptulose are promising candidate BFIs for avocado but again, larger population studies are required to document their robustness and reliability. A few human intervention studies with mango, papaya, pomegranate, and dates have been performed, but no candidate BFIs were identified so far for these fruits. Specific phytochemicals have been described in some tropical fruits including mango, pineapple, guava, and persimmon, but there is virtually no information regarding their bioavailability and interest as putative BFIs.

The way forward for discovering BFIs for tropical fruits is certainly the application of untargeted metabolomics, where no a priori hypothesis of candidate biomarkers is required. Complementary studies with different study design, such as controlled cross-over trials with different doses of the fruits, and cross-sectional studies with comprehensive dietary information will have to be used to document the criteria of the validation scheme for BFIs.

In parallel, data collection and sharing in online resources on the phytochemical composition of tropical fruits and the bioavailability of these phytochemicals should facilitate the identification of specific phytochemical metabolites in metabolomic profiles that may constitute new candidate BFIs.

\section{Supplementary information}

Supplementary information accompanies this paper at https://doi.org/10. 1186/s12263-020-00670-4

Additional file 1: Table S1. Validation criteria for biomarkers of food intake as established by Dragsted et al.

Additional file 2: Table S2. Summary of selected candidate, putative and excluded biomarkers of food intake tropical fruits, measured in biofluids ${ }^{1}$.

Additional file 3: Figure S1. Specific compounds found in different tropical fruits that may be further explored as putative BFIs in human studies.

\section{Abbreviations}

BFIRev: Biomarker of Food Intake Reviews; BFI: Biomarker of food intake; HILIC-QTRAP-MSMS: Hydrophilic interaction liquid chromatographyquadrupole ion trap-mass spectrometry; HPLC: High-performance liquid chromatography; DAD: Diode-array-detection; ECD: Electrochemical detection; ESI-MS: Electron spray ionization-mass spectrometry; UV: Ultraviolet detection; MS: Mass spectrometry; QqQ: Triple quadrupolemass spectrometry; GC: Gas-chromatography; GCxGC: Two dimensional-gas chromatography; UHPLC: Ultra-performance liquid chromatography;
QTOF: Quadrupole-time of flight-mass spectrometry; 6-OH-MTßC-sulfate: 6Hydroxy-1-methyl-1,2,3,4-tetrahydro- $\beta$-carboline sulfate

\section{Acknowledgements \\ Not applicable.}

\section{Authors' contributions}

This manuscript was drafted by NVM, LOD, and CM. All other authors critically commented the manuscript and approved the final manuscript.

\section{Funding}

The Food Biomarkers Alliance (FoodBAll) is a project funded under the Joint Action Biomarkers in Nutrition and Health of the Joint Programming Initiative "A Healthy Diet for a Healthy Life," by the respective national Research Councils; the work was funded in part by a grant from the French Agence Nationale de la Recherche (\#ANR-14-HDHL-0002-02) to CM, a PhD grant from INRA for NVM, from the Danish Innovation Foundation (\#420300002B) to LOD, a postdoc grant from the University of Rome La Sapienza ("Borsa di studio per la frequenza di corsi o attività di perfezionamento all'estero" erogata ai sensi della legge 398/89) to GP, a grant from the Ministry of Economy and Competitiveness (MINECO) (PCIN-2014-133-MINECO Spain), an award from the Generalitat de Catalunya's Agency AGAUR (2017SGR1566), and funds from CIBERFES (co-funded by the FEDER Program from EU) to MGA; the Ministry of Education, University and Research, MIUR (decreto n.2075 of 18/09/2015) to MU and FM.

Availability of data and materials

Not applicable.

Ethics approval and consent to participate

Not applicable.

Consent for publication

Not applicable.

\section{Competing interests}

The authors declare that they have no competing interests.

\section{Author details}

${ }^{1}$ Human Nutrition Unit, Université Clermont Auvergne, INRAE, F-63000 Clermont-Ferrand, France. 'Department of Nutrition, Exercise and Sports, University of Copenhagen, Copenhagen, Denmark. ${ }^{3}$ Dirección de Nutrición, Instituto Nacional de Ciencias Médicas y Nutrición Salvador Zubirán, Mexico City, Mexico. ${ }^{4}$ Research and Innovation Centre Food Quality and Nutrition, Fondazione Edmund Mach, Via Mach 1, 38010 San Michele all'Adige, Italy. ${ }^{5}$ Biomarkers and Nutrimetabolomic Laboratory, Department of Nutrition, Food Sciences and Gastronomy, XaRTA, INSA, Faculty of Pharmacy and Food Sciences, Campus Torribera, University of Barcelona, Barcelona, Spain. ${ }^{6} \mathrm{CIBER}$ de Fragilidad y Envejecimiento Saludable (CIBERFES), Instituto de Salud Carlos III, Barcelona, Spain. ${ }^{7}$ Department of Cellular, Computational and Integrative Biology, CIBIO, University of Trento, San Michele all'Adige, Italy.

Received: 8 January 2020 Accepted: 2 June 2020

Published online: 19 June 2020

\section{References}

1. Dembitsky VM, Poovarodom S, Leontowicz H, Leontowicz M, Vearasilp S, Trakhtenberg $\mathrm{S}$, et al. The multiple nutrition properties of some exotic fruits: biological activity and active metabolites. Food Res Int. 2011;44(7):1671-701.

2. Food Agriculture Organization of the United Nations. [cited 201922 December]; Available from: http://faostat.fao.org/.

3. Alterndorf S. Major tropical fruits market review 2017. Rome: FAO; 2019. p. 10.

4. Sahebkar A, Ferri C, Giorgini P, Bo S, Nachtigal P, Grassi D. Effects of pomegranate juice on blood pressure: a systematic review and metaanalysis of randomized controlled trials. Pharmacol Res. 2017;115:149-61.

5. Garcia-Conesa MT, Chambers K, Combet E, Pinto P, Garcia-Aloy M, AndresLacueva C, de Pascual-Teresa S, Mena P, Konic Ristic A, Hollands WJ, et al. Meta-analysis of the effects of foods and derived products containing ellagitannins and anthocyanins on cardiometabolic biomarkers: analysis of 
factors influencing variability of the individual responses. Int. J. Mol. Sci. 2018;19(3).

6. Espin J, Larrosa M, Garcia-Conesa MT, Tomas-Barberan F. Biological significance of urolithins, the gut microbial ellagic acid-derived metabolites: the evidence so far. Evid Based Complement Alternat Med. 2013;2013:15.

7. Bingham S, Luben R, Welch A, Low YL, Khaw KT, Wareham N, et al. Associations between dietary methods and biomarkers, and between fruits and vegetables and risk of ischaemic heart disease, in the EPIC Norfolk cohort study. Int J Epidemiol. 2008;37(5):978-87.

8. Thompson FE, Midthune D, Kahle L, Dodd KW. Development and evaluation of the National Cancer Institute's dietary screener questionnaire scoring algorithms. J Nutr. 2017;147(6):1226-33.

9. Subar AF, Thompson FE, Kipnis V, Midthune D, Hurwitz P, McNutt S, et al. Comparative validation of the block, Willett, and National Cancer Institute food frequency questionnaires : the eating at America's table study. Am J Epidemiol. 2001;154(12):1089-99.

10. Denova-Gutiérrez E, Tucker KL, Salmerón J, Flores M, Barquera S. Relative validity of a food frequency questionnaire to identify dietary patterns in an adult Mexican population. 2016. 2016;58(6):9.

11. Henn RL, Fuchs SC, Moreira LB, Fuchs FD. Development and validation of a food frequency questionnaire (FFQ-Porto Alegre) for adolescent, adult and elderly populations from southern Brazil. Cad Saude Publica. 2010;26:206879.

12. Neelakantan N, Whitton C, Seah S, Koh H, Rebello SA, Lim JY, et al. Development of a semi-quantitative food frequency questionnaire to assess the dietary intake of a multi-ethnic urban asian population. Nutrients. 2016; 8(9):528.

13. Gao Q, Praticò G, Scalbert A, Vergères G, Kolehmainen M, Manach C, et al. A scheme for a flexible classification of dietary and health biomarkers. Genes Nutr. 2017;12:34

14. Baldrick FR, Woodside JV, Elborn JS, Young IS, McKinley MC. Biomarkers of fruit and vegetable intake in human intervention studies: a systematic review. Crit Rev Food Sci Nutr. 2011;51(9):795-815.

15. Clinton SK, Unlu NZ, Bohn T, Schwartz SJ. Carotenoid absorption from salad and salsa by humans is enhanced by the addition of avocado or avocado oil. J Nutr. 2005;135(3):431-6.

16. Huang C, Tang YL, Chen CY, Chen ML, Chu CH, Hseu CT. The bioavailability of beta-carotene in stir- or deep-fried vegetables in men determined by measuring the serum response to a single ingestion. J Nutr. 2000;130(3): 534-40.

17. Levine M, Padayatty SJ, Espey MG, et al. Advances in nutrition (Bethesda, Md). 2011;2(2):78-88.

18. Karlsen A, Blomhoff R, Gundersen TE. Stability of whole blood and plasma ascorbic acid. Eur J Clin Nutr. 2007;61(10):1233-6.

19. Praticò G, Gao Q, Scalbert A, Vergères G, Kolehmainen M, Manach C, et al. Guidelines for biomarker of food intake reviews (BFIRev): how to conduct an extensive literature search for biomarker of food intake discovery. Genes Nutr. 2018;13(1):3.

20. Dragsted LO, Gao Q, Scalbert A, Vergères G, Kolehmainen M, Manach C, et al. Validation of biomarkers of food intake-critical assessment of candidate biomarkers. Genes Nutr. 2018;13:14.

21. Dictionary of Food compounds [database on the Internet]. CRC Press Taylor ad Francis Group. 2018. Available from: http://dfc.chemnetbase.com/faces/ chemical/ChemicalSearch.xhtml.

22. FooDB [database on the Internet]. Available from: http://foodb.ca/.

23. KNApSAck [database on the Internet]. Available from: http://www. knapsackfamily.com/KNApSAcK_Family/.

24. Liu Y, Liang Y, Wishart D. PolySearch2: a significantly improved text-mining system for discovering associations between human diseases, genes, drugs, metabolites, toxins and more. Nucleic Acids Res. 2015;43(W1):W535-42.

25. Coremine medical online database [database on the Internet]. Available from: http://www.coremine.com/medical/

26. Dragsted LO, Gao Q, Pratico G, Manach C, Wishart DS, Scalbert A, et al. Dietary and health biomarkers-time for an update. Genes Nutr. 2017;12:24.

27. Wishart DS, Feunang YD, Marcu A, Guo AC, Liang K, Vazquez-Fresno R, et al. HMDB 4.0: the human metabolome database for 2018. Nucleic Acids Res. 2018;46(D1):D608-d17.

28. Medina-Remón A, Manach C, Knox C, Wishart DS, Perez-Jimenez J, Rothwell JA, et al. Phenol-explorer 3.0: a major update of the phenol-explorer database to incorporate data on the effects of food processing on polyphenol content. Database. 2013;2013.
29. Dr. Duke's Phytochemical and Ethnobotanical Databases [database on the Internet]. 1992-2016. Available from: http://phytochem.nal.usda.gov/.

30. Plumb J, Pigat S, Bompola F, Cushen M, Pinchen H, Nørby E, et al. eBASIS (bioactive substances in food information systems) and bioactive intakes: major updates of the bioactive compound composition and beneficial bioeffects database and the development of a probabilistic model to assess intakes in Europe. Nutrients. 2017;9(4):320.

31. Phytohub [database on the Internet]. Available from: http://phytohub.eu/.

32. Feldman $J M$, Lee EM. Serotonin content of foods: effect on urinary excretion of 5-hydroxyindoleacetic acid. Am J Clin Nutr. 1985;42(4):639-43.

33. Lewis CE. Timed excretion of 5-Hydroxy Indoleacetic acid after Oral Administration of Bananas and 5-Hydroxytryptamine. Proc Soc Exp Biol Med. 1958;99(2):523-5.

34. Helander A, Some M. Dietary serotonin and alcohol combined may provoke adverse physiological symptoms due to 5-hydroxytryptophol. Life Sci. 2000; 67(7):799-806.

35. Helander A, Wikstrom T, Lowenmo C, Jacobsson G, Beck O. Urinary excretion of 5-hydroxyindole-3-acetic acid and 5-hydroxytryptophol after oral loading with serotonin. Life Sci. 1992;50(17):1207-13.

36. Odink J, Korthals H, Knijff JH. Simultaneous determination of the major acidic metabolites of catecholamines and serotonin in urine by liquid chromatography with electrochemical detection after a one-step sample clean-up on Sephadex G-10; influence of vanilla and banana ingestion. J Chromatogr. 1988;424(2):273-83.

37. Numata K, Kusui H, Kawakatsu H, Kizaki Z, Sawada T. Increased urinary HVA levels in neuroblastoma screens related to diet, not tumor. Pediatr Hematol Oncol. 1997;14(6):569-76.

38. Mashige F, Matsushima Y, Kanazawa H, Sakuma I, Takai N, Bessho F, et al. Acidic catecholamine metabolites and 5-hydroxyindoleacetic acid in urine: the influence of diet. Ann Clin Biochem. 1996;33(Pt 1):43-9.

39. Perry $T L$, Hansen $S$, Hestrin M, Maclntyre L. Exogenous urinary amines of plant origin. Clin Chim Acta. 1965;11(1):24-34.

40. Crout JR, Sjoerdsma A. The clinical and laboratory significance of serotonin and cathecolamines in bananas. N Engl J Med. 1959;261(1):23-6.

41. Tohmola N, Johansson A, Sane T, Renkonen R, Hamalainen E, Itkonen O Transient elevation of serum 5-HIAA by dietary serotonin and distribution of 5-HIAA in serum protein fractions. Ann Clin Biochem. 2015;52(Pt 4):428-33.

42. Nieman DC, Gillitt ND, Sha W, Meaney MP, John C, Pappan KL, et al. Metabolomics-based analysis of banana and pear ingestion on exercise performance and recovery. J Proteome Res. 2015;14(12):5367-77.

43. Lee J, Ramchandani VA, Hamazaki K, Engleman EA, McBride WJ, Li TK, et al. A critical evaluation of influence of ethanol and diet on salsolinol enantiomers in humans and rats. Alcohol Clin Exp Res. 2010;34(2):242-50.

44. Nieman DC, Gillitt ND, Henson DA, Sha W, Shanely RA, Knab AM, CialdellaKam L, Jin F. Bananas as an energy source during exercise: a metabolomics approach. PLoS One. 2012;7(5).

45. Strolin Benedetti M, Dostert P, Carminati P. Influence of food intake on the enantiomeric composition of urinary salsolinol in man. J Neural Transm Gen Sect. 1989;78(1):43-51.

46. Tazoe M, Narita M, Sakuta R, Nagai T, Narita N. Hyperkalemia and hyperdopaminemia induced by an obsessive eating of banana in an anorexia nervosa adolescent. Brain and Development. 2007;29(6):369-72.

47. Nieman DC, Gillitt ND, Sha W, Esposito D, Ramamoorthy S. Metabolic recovery from heavy exertion following banana compared to sugar beverage or water only ingestion: a randomized, crossover trial. PLoS One. 2018;13(3).

48. Wang Y, Gapstur SM, Carter BD, Hartman TJ, Stevens VL, Gaudet MM, et al. Untargeted metabolomics identifies novel potential biomarkers of habitual food intake in a cross-sectional study of postmenopausal women. J Nutr. 2018;148(6):932-43.

49. Vázquez-Manjarrez $\mathrm{N}$, Weinert $\mathrm{CH}$, Ulaszewska M, Pétéra M, Micheau P, Durand $\mathrm{S}$, et al. Discovery and validation of banana intake biomarkers using untargeted metabolomics. J Nutr. 2019;149(10):1701-13.

50. Mandel H, Levy N, Izkovitch S, Korman SH. Elevated plasma citrulline and arginine due to consumption of Citrullus vulgaris (watermelon). J Inherit Metab Dis. 2005;28(4):467-72.

51. Bailey SJ, Blackwell JR, Williams E, Vanhatalo A, Wylie LJ, Winyard PG, et al. Two weeks of watermelon juice supplementation improves nitric oxide bioavailability but not endurance exercise performance in humans. Nitric Oxide. 2016;59:10-20.

52. Shanely RA, Nieman DC, Perkins-Veazie P, Henson DA, Meaney MP, Knab AM, Cialdell-Kam L. Comparison of watermelon and carbohydrate beverage 
on exercise-induced alterations in systemic inflammation, immune dysfunction, and plasma antioxidant capacity. Nutrients. 2016;8(8).

53. Collins JK, Wu G, Perkins-Veazie P, Spears K, Claypool PL, Baker RA, et al. Watermelon consumption increases plasma arginine concentrations in adults. Nutrition. 2007;23(3):261-6.

54. Mack Cl, Weinert $\mathrm{CH}$, Egert B, Ferrario PG, Bub A, Hoffmann I, et al. The complex human urinary sugar profile: determinants revealed in the crosssectional KarMeN study. Am J Clin Nutr. 2018;108(3):502-16.

55. Wamelink MM, Smith DE, Jansen EE, Verhoeven NM, Struys EA, Jakobs C. Detection of transaldolase deficiency by quantification of novel sevencarbon chain carbohydrate biomarkers in urine. J Inherit Metab Dis. 2007; 30(5):735-42.

56. The EFSA Comprehensive European Food Consumption Database [database on the Internet]. 2011. Available from: https://www.efsa.europa.eu/en/foodconsumption/comprehensive-database.

57. Food and Agriculture Organization of the United Nations. Banana Market Review 2015-2016. Rome2017.

58. Tulipani S, Llorach R, Jáuregui O, López-Uriarte P, Garcia-Aloy M, Bullo M, et al. Metabolomics unveils urinary changes in subjects with metabolic syndrome following 12-week nut consumption. J Proteome Res. 2011; 10(11):5047-58

59. Garcia-Aloy M, Hulshof PJM, Estruel-Amades S, Osté MCJ, Lankinen M, Geleijnse JM, et al. Biomarkers of food intake for nuts and vegetable oils: an extensive literature search. Genes Nutr. 2019;14(1):7.

60. Hano S, Shibuya T, Imoto N, Ito A, Imanishi S, Aso H, et al. Serotonin content in fresh and processed tomatoes and its accumulation during fruit development. Sci Hortic. 2017;214:107-13.

61. Tohmola N, Itkonen O, Sane T, Markkanen H, Joenväärä S, Renkonen R, et al. Analytical and preanalytical validation of a new mass spectrometric serum 5-hydroxyindoleacetic acid assay as neuroendocrine tumor marker. Clin Chim Acta. 2014;428:38-43.

62. Shihabi ZK, Scaro J. Liquid-chromatographic assay of urinary 5-hydroxy-3indoleacetic acid, with electrochemical detection. Clin Chem. 1980;26(7):907.

63. van Haard PMM, Wielders JPM, Wikkerink JBW. Direct concurrent measurement of urinary vanillylmandelic acid, 5-hydroxyindoleacetic acid and homovanillic acid by HPLC. Three methodologies compared. Biomed. Chromatogr. 1987;2(5):209-15.

64. Laboratories MCM. Urine preservatives-collection and transportation for 24-hour urine specimens, 2015. 2015.

65. Feldman JM, Lee EM, Castleberry CA. Catecholamine and serotonin content of foods-effect on urinary excretion of homovanillic and 5hydroxyindoleacetic acid. J Am Diet Assoc. 1987;87(8):1031-5.

66. Meiser J, Weindl D, Hiller K. Complexity of dopamine metabolism. Cell Commun Signal. 2013;11:34.

67. Yamamoto T, Yamatodani A, Nishimura M, Wada H. Determination of dopamine-3- and -4-O-sulphate in human plasma and urine by anionexchange high-performance liquid chromatography with fluorimetric detection. J. Chromatogr. B Biomed. Sci. Appl. 1985;342:261-7.

68. Goldstein DS, Swoboda KJ, Miles JM, Coppack SW, Aneman A, Holmes C, et al. Sources and physiological significance of plasma dopamine sulfate. J Clin Endocrinol Metab. 1999;84(7):2523-31.

69. Eisenhofer G, Aneman A, Friberg P, Hooper D, Fandriks L, Lonroth $H$, et al. Substantial production of dopamine in the human gastrointestinal tract. J Clin Endocrinol Metab. 1997;82(11):3864-71.

70. Davidson L, Vandongen R, Beilin $\sqcup$. Effect of eating bananas on plasma free and sulfate-conjugated catecholamines. Life Sci. 1981;29(17):1773-8.

71. Peitzsch M, Pelzel D, Lattke P, Siegert G, Eisenhofer G. Preservation of urine free catecholamines and their free O-methylated metabolites with citric acid as an alternative to hydrochloric acid for LC-MS/MS-based analyses. Clin Chem Lab Med. 2016;54(1):37-43.

72. Chan ECY, Wee PY, Ho PC. Evaluation of degradation of urinary catecholamines and metanephrines and deconjugation of their sulfoconjugates using stability-indicating reversed-phase ion-pair HPLC with electrochemical detection. J Pharm Biomed Anal. 2000;22(3):515-26.

73. Rommelspacher H, Sllstrom Baum S, Dufeu P, Schmidt LG. Determination of (R)- and (S)-salsolinol sulfate and dopamine sulfate levels in plasma of nonalcoholics and alcoholics. Alcohol. 1995;12(4):309-15.

74. Adaway JE, Peitzsch M, Keevil BG. A novel method for the measurement of plasma metanephrines using online solid phase extraction-liquid chromatography tandem mass spectrometry. Ann Clin Biochem. 2014;52(3): 361-9.
75. Sojo MM, Nuñez-Delicado E, Sánchez-Ferrer A, García-Carmona F. Oxidation of salsolinol by banana pulp polyphenol oxidase and its kinetic synergism with dopamine. J Agric Food Chem. 2000;48:5543-7.

76. Kurnik-Łucka M, Panula P, Bugajski A, Gil K. Salsolinol: an unintelligible and double-faced molecule-lessons learned from in vivo and in vitro experiments. Neurotox Res. 2018;33:485-514.

77. Duncan MW, Smythe GA, Nicholson MV, Clezy PS. Comparison of highperformance liquid chromatography with electrochemical detection and gas chromatography - mass fragmentography for the assay of salsolinol, dopamine and dopamine metabolites in food and beverage samples. J Chromatogr B Biomed Sci Appl. 1984;336:199-209.

78. Makino Y, Tasaki Y, Ohta S, Hirobe M. Confirmation of the enantiomers of 1methyl-1,2,3,4-tetrahydroisoquinoline in the mouse brain and foods applying gas chromatography/mass spectrometry with negative ion chemical ionization. Biomed Environ Mass Spectrom. 1990;19(7):415-9.

79. Deng Y, Maruyama W, Kawai M, Dostert P, Yamamura H, Takahashi T, et al. Assay for the (R)- and (S)-enantiomers of salsolinols in biological samples and foods with ion-pair high-performance liquid chromatography using $\beta$ cyclodextrin as a chiral mobile phase additive. J. Chromatogr. B Biomed. Sci. Appl. 1997;689:313-20.

80. Melzig MF, Putscher I, Henklein $\mathrm{P}$, Haber $\mathrm{H}$. In vitro pharmacological activity of the tetrahydroisoquinoline salsolinol present in products from Theobroma cacao L. like cocoa and chocolate. J. Ethnopharmacol. 2000;73:153-9.

81. Hirst M, Evans DR, Gowdey CW. Salsolinol in urine following chocolate consumption by social drinkers. Alcohol Drug Res. 1987;7(5-6):493-501.

82. Beyer J, Ehlers D, Maurer HH. Abuse of nutmeg (Myristica fragrans Houtt.): studies on the metabolism and the toxicologic detection of its ingredients elemicin, myristicin, and safrole in rat and human urine using gas chromatography/mass spectrometry. Ther. Drug Monit. 2006;28:568-75.

83. Howes MJ, Kite GC, Simmonds MS. Distinguishing Chinese star anise from Japanese star anise using thermal desorption-gas chromatography-mass spectrometry. J Agric Food Chem. 2009;57(13):5783-9.

84. Herraiz TGJ. Tetrahydro-b-carboline alkaloids occur in fruits and fruit juices. Activity as antioxidants and radical scavengers. J Agric Food Chem. 2003;51:7156-61.

85. Herraiz T. Tetrahydro-beta-carbolines, potential neuroactive alkaloids, in chocolate and cocoa. J Agric Food Chem. 2000;48(10):4900-4.

86. Ulaszewska M, Vazquez-Manjarrez N, Garcia-Aloy M, Llorach R, Mattivi F, Dragsted LO, et al. Food intake biomarkers for apple, pear, and stone fruit. Genes Nutr. 2018;13:29.

87. Sae-Teaw M, Johns J, Johns NP, Subongkot S. Serum melatonin levels and antioxidant capacities after consumption of pineapple, orange, or banana by healthy male volunteers. J Pineal Res. 2013;55(1):58-64.

88. Garrido M, Paredes SD, Cubero J, Lozano M, Toribio-Delgado AF, Munoz JL, et al. Jerte Valley cherry-enriched diets improve nocturnal rest and increase 6-sulfatoxymelatonin and total antioxidant capacity in the urine of middleaged and elderly humans. J Gerontol A Biol Sci Med Sci. 2010;65(9):909-14.

89. Carrasco-Pozo C, Gotteland M, Castillo RL, Chen C. 3,4-

Dihydroxyphenylacetic acid, a microbiota-derived metabolite of quercetin, protects against pancreatic beta-cells dysfunction induced by high cholesterol. Exp Cell Res. 2015;334(2):270-82.

90. Combet E, Lean ME, Boyle JG, Crozier A, Davidson DF. Dietary flavonols contribute to false-positive elevation of homovanillic acid, a marker of catecholamine-secreting tumors. Clin Chim Acta. 2011;412(1-2):165-9.

91. Moing A, Aharoni A, Biais B, Rogachev I, Meir S, Brodsky L, et al. Extensive metabolic cross-talk in melon fruit revealed by spatial and developmental combinatorial metabolomics. New Phytol. 2011;190(3):683-96.

92. Abu-Reidah IM, Contreras MM, Arráez-Román D, Segura-Carretero A, Fernández-Gutiérrez A. Reversed-phase ultra-high-performance liquid chromatography coupled to electrospray ionization-quadrupole-time-offlight mass spectrometry as a powerful tool for metabolic profiling of vegetables: Lactuca sativa as an example of its application. J Chromatogr A. 2013;1313:212-27.

93. Cichon MJ, Riedl KM, Schwartz SJ. A metabolomic evaluation of the phytochemical composition of tomato juices being used in human clinical trials. Food Chem. 2017;228:270-8.

94. S. C. Sri Harsha P, Abdul Wahab R, Cuparencu C, Dragsted OL, Brennan L. A metabolomics approach to the identification of urinary biomarkers of pea intake. Nutrients. 2018;10(12).

95. Pallister T, Jennings A, Mohney RP, Yarand D, Mangino M, Cassidy A, et al. Characterizing blood metabolomics profiles associated with self-reported food intakes in female twins. PLoS One. 2016;11(6):e0158568. 
96. Badawy AAB. Kynurenine pathway of tryptophan metabolism: regulatory and functional aspects. international journal of tryptophan research : IJTR. 2017;10:1178646917691938-.

97. National Food Institute D. Frida Food Data. [cited 3]; 01-05-2018:[Available from: https://frida.fooddata.dk/?lang = en.

98. Münger LH, Garcia-Aloy M, Vázquez-Fresno R, Gille D, Rosana ARR, Passerini $A$, et al. Biomarker of food intake for assessing the consumption of dairy and egg products. Genes Nutr. 2018;13(1):26.

99. Edwards AJ, Vinyard BT, Wiley ER, Brown ED, Collins JK, Perkins-Veazie P, et al. Consumption of watermelon juice increases plasma concentrations of lycopene and beta-carotene in humans. J Nutr. 2003;133(4):1043-50.

100. Gouado I, Schweigert FJ, Ejoh RA, Tchouanguep MF, Camp JV. Systemic levels of carotenoids from mangoes and papaya consumed in three forms (juice, fresh and dry slice). Eur J Clin Nutr. 2007;61(10):1180-8.

101. Irwig MS, El-Sohemy A, Baylin A, Rifai N, Campos H. Frequent intake of tropical fruits that are rich in beta-cryptoxanthin is associated with higher plasma beta-cryptoxanthin concentrations in costa Rican adolescents. J Nutr. 2002;132(10):3161-7.

102. Schweiggert RM, Kopec RE, Villalobos-Gutierrez MG, Högel J, Quesada S, Esquivel $P$, et al. Carotenoids are more bioavailable from papaya than from tomato and carrot in humans: a randomised cross-over study. $\mathrm{Br} J$ Nutr. 2014;111(3):490-8.

103. Maiani G, Caston MJ, Catasta G, Toti E, Cambrodon IG, Bysted A, et al. Carotenoids: actual knowledge on food sources, intakes, stability and bioavailability and their protective role in humans. Mol Nutr Food Res. 2009 . 53(Suppl 2):S194-218.

104. Hendrickson SJ, Willett WC, Rosner BA, Eliassen AH. Food predictors of plasma carotenoids. Nutrients. 2013;5(10):4051-66.

105. Murillo E, Giuffrida D, Menchaca D, Dugo P, Torre G, Meléndez-Martinez AJ, et al. Native carotenoids composition of some tropical fruits. Food Chem. 2013;140(4):825-36.

106. Kaore SN, Kaore NM. Chapter 53 - Citrulline: pharmacological perspectives and role as a biomarker in diseases and toxicities. In: Gupta RC, editor. Biomarkers in toxicology. Boston: Academic Press; 2014. p. 883-905.

107. Dreher ML, Davenport AJ. Hass avocado composition and potential health effects. Crit Rev Food Sci Nutr. 2013;53(7):738-50.

108. Al-Alawi RA, Al-Mashiqri JH, Al-Nadabi JSM, Al-Shihi BI, Baqi Y. Date palm tree (Phoenix dactylifera L.): natural products and therapeutic options. Front Plant Sci. 2017;8(845).

109. Vayalil PK. Date fruits (Phoenix dactylifera Linn): An emerging medicinal food. Crit Rev Food Sci Nutr. 2012;52(3):249-71.

110. Mathew S, Halama A, Kader SA, Choe M, Mohney RP, Malek JA, et al. Metabolic changes of the blood metabolome after a date fruit challenge. J Funct Foods. 2018;49:267-76

111. Sharma C, Kaur A, Thind SS, Singh B, Raina S. Advanced glycation endproducts (AGEs): an emerging concern for processed food industries. J Food Sci Technol. 2015:52(12):7561-76.

112. Aragno M, Mastrocola R. Dietary sugars and endogenous formation of advanced glycation endproducts: emerging mechanisms of disease. Nutrients. 2017;9.

113. Maier VP, Metzler DM, Huber AF. 3-0-Caffeoylshikimic acid (dactylifric acid) and its isomers, a new class of enzymic browning substrates. Biochem Biophys Res Commun. 1964;14(2):124-8.

114. Mansouri A, Embarek G, Kokkalou E, Kefalas P. Phenolic profile and antioxidant activity of the Algerian ripe date palm fruit (Phoenix dactylifera). Food Chem. 2005:89(3):411-20.

115. Truchado P, Larrosa M, Garcia-Conesa MT, Cerda B, Vidal-Guevara ML, Tomas-Barberan FA, et al. Strawberry processing does not affect the production and urinary excretion of urolithins, ellagic acid metabolites, in humans. J Agric Food Chem. 2012;60(23):5749-54.

116. Tomás-Barberán FA, García-Villalba R, González-Sarrías A, Selma MV, Espín JC. Ellagic acid metabolism by human gut microbiota: consistent observation of three urolithin phenotypes in intervention trials, independent of food source, age, and health status. J Agric Food Chem. 2014;62(28):6535-8.

117. Cerdá B, Tomás-Barberán FA, Espín JC. Metabolism of antioxidant and chemopreventive ellagitannins from strawberries, raspberries, walnuts, and oak-aged wine in humans: identification of biomarkers and individual variability. J Agric Food Chem. 2005;53(2):227-35.

118. Espín JC, Larrosa M, García-Conesa MT, Tomás-Barberán F. Biological significance of urolithins, the gut microbial ellagic Acid-derived metabolites: the evidence so far. Evid Based Complement Alternat Med. 2013;2013: 270418
119. Garcia-Villalba R, Carlos Espin J, Tomas-Barberan FA. Chromatographic and spectroscopic characterization of urolithins for their determination in biological samples after the intake of foods containing ellagitannins and ellagic acid. J Chromatogr A. 2016;1428:162-75.

120. Gonzalez-Sarrias A, Carlos Espin J, Tomas-Barberan FA. Non-extractable polyphenols produce gut microbiota metabolites that persist in circulation and show anti-inflammatory and free radical-scavenging effects. Trends Food Sci Technol. 2017;69:281-8.

121. Gonzalez-Sarrias A, Garcia-Villalba R, Romo-Vaquero M, Alasalvar C, Orem A, Zafrilla P, Tomas-Barberan FA, Selma MV, Espin JC. Clustering according to urolithin metabotype explains the interindividual variability in the improvement of cardiovascular risk biomarkers in overweight-obese individuals consuming pomegranate: a randomized clinical trial. Mol Nutr Food Res. 2017;61(5).

122. Gonzalez-Sarrias A, Nunez-Sanchez MA, Avila-Galvez MA, Monedero-Saiz T, Rodriguez-Gil FJ, Martinez-Diaz F, et al. Consumption of pomegranate decreases plasma lipopolysaccharide-binding protein levels, a marker of metabolic endotoxemia, in patients with newly diagnosed colorectal cancer: a randomized controlled clinical trial. Food Funct. 2018;9(5):2617-22.

123. Roberts KM, Grainger EM, Thomas-Ahner JM, Hinton A, Gu J, Riedl KM, Vodovotz Y, Abaza R, Schwartz SJ, Clinton SK. Application of a low polyphenol or low ellagitannin dietary intervention and its impact on ellagitannin metabolism in men. Mol. Nutr. Food Res. 2017;61(3).

124. Selma MV, Gonzalez-Sarrias A, Salas-Salvado J, Andres-Lacueva C, Alasalvar C, Orem A, et al. The gut microbiota metabolism of pomegranate or walnut ellagitannins yields two urolithin-metabotypes that correlate with cardiometabolic risk biomarkers: comparison between normoweight, overweight-obesity and metabolic syndrome. Clin Nutr. 2018;37(3):897-905.

125. Yang J, Lee R, Henning SM, Thames G, Hsu M, ManLam H, et al. Soy protein isolate does not affect ellagitannin bioavailability and urolithin formation when mixed with pomegranate juice in humans. Food Chem. 2016;194: 1300-3.

126. Yang $X$, Tomas-Barberan FA. Tea is a significant dietary source of ellagitannins and ellagic acid. J Agric Food Chem. 2019;67(19):5394-404.

127. Tomas-Barberan FA, Gonzalez-Sarrias A, Garcia-Villalba R, Nunez-Sanchez MA, Selma MV, Garcia-Conesa MT, Espin JC. Urolithins, the rescue of "old" metabolites to understand a "new" concept: Metabotypes as a nexus among phenolic metabolism, microbiota dysbiosis, and host health status. Mol Nutr Food Res. 2017:61(1).

128. Gonzalez-Sarrias A, Gimenez-Bastida JA, Garcia-Conesa MT, Gomez-Sanchez MB, Garcia-Talavera NV, Gil-Izquierdo A, et al. Occurrence of urolithins, gut microbiota ellagic acid metabolites and proliferation markers expression response in the human prostate gland upon consumption of walnuts and pomegranate juice. Mol Nutr Food Res. 2010;54(3):311-22.

129. Yang $X$, Tomás-Barberán FA. Tea is a significant dietary source of ellagitannins and ellagic acid. J Agric Food Chem. 2019;67(19):5394-404

130. Nunez-Sanchez MA, Garcia-Villalba R, Monedero-Saiz T, Garcia-Talavera NV, GomezSanchez MB, Sanchez-Alvarez C, et al. Targeted metabolic profiling of pomegranate polyphenols and urolithins in plasma, urine and colon tissues from colorectal cancer patients. Mol Nutr Food Res. 2014;58(6):1199-211.

131. Puupponen-Pimia R, Seppanen-Laakso T, Kankainen M, Maukonen J, Torronen $\mathrm{R}$, Kolehmainen $\mathrm{M}$, et al. Effects of ellagitannin-rich berries on blood lipids, gut microbiota, and urolithin production in human subjects with symptoms of metabolic syndrome. Mol Nutr Food Res. 2013;57(12): 2258-63.

132. Luo F, Lv Q, Zhao Y, Hu G, Huang G, Zhang J, et al. Quantification and purification of mangiferin from Chinese mango (Mangifera indica L.) cultivars and its protective effect on human umbilical vein endothelial cells under $\mathrm{H}(2) \mathrm{O}(2)$-induced stress. Int. J Mol Sci. 2012;13(9):11260-74.

133. Quiros-Sauceda AE, Chen CO, Blumberg JB, Astiazaran-Garcia H, WallMedrano A, Gonzalez-Aguilar GA. Processing 'Ataulfo' Mango into Juice Preserves the Bioavailability and Antioxidant Capacity of Its Phenolic Compounds. Nutrients. 2017;9(10).

134. Barnes RC, Krenek KA, Meibohm B, Mertens-Talcott SU, Talcott ST. Urinary metabolites from mango (Mangifera indica L. cv. Keitt) galloyl derivatives and in vitro hydrolysis of gallotannins in physiological conditions. Mol Nutr Food Res. 2016;60(3):542-50.

135. Pimpao RC, Dew T, Figueira ME, McDougall GJ, Stewart D, Ferreira RB, et al. Urinary metabolite profiling identifies novel colonic metabolites and conjugates of phenolics in healthy volunteers. Mol Nutr Food Res. 2014; 58(7):1414-25. 
136. Feliciano RP, Boeres A, Massacessi L, Istas G, Ventura MR, Nunes dos Santos C, Heiss C, Rodriguez-Mateos A. Identification and quantification of novel cranberry-derived plasma and urinary (poly)phenols. Arch Biochem Biophys. 2016:599:31-41.

137. Stalmach A, Edwards CA, Wightman JD, Crozier A. Colonic catabolism of dietary phenolic and polyphenolic compounds from Concord grape juice. Food Funct. 2013;4(1):52-62.

138. Abdul Hamid NA, Mediani A, Maulidiani M, Abas F, Park YS, Leontowicz H, et al. Characterization of metabolites in different kiwifruit varieties by NMR and fluorescence spectroscopy. J Pharm Biomed Anal. 2017;138:80-91.

139. Zhou Y, Ma Y, Zeng J, Duan L, Xue X, Wang H, et al. Convergence and divergence of bitterness biosynthesis and regulation in Cucurbitaceae. Nat Plants. 2016;2:16183.

140. Qin X-J, Yu Q, Yan H, Khan A, Feng M-Y, Li P-P, et al. Meroterpenoids with antitumor activities from guava (Psidium guajava). J Agric Food Chem. 2017; 65(24):4993-9.

141. Pujos-Guillot E, Hubert J, Martin J-F, Lyan B, Quintana M, Claude S, et al. Mass spectrometry-based metabolomics for the discovery of biomarkers of fruit and vegetable intake: citrus fruit as a case study. J Proteome Res. 2013; 12(4):1645-59.

142. Kohlert C, van Rensen I, Marz R, Schindler G, Graefe EU, Veit M.

Bioavailability and pharmacokinetics of natural volatile terpenes in animals and humans. Planta Med. 2000;66(6):495-505.

143. Johns NP, Johns J, Porasuphatana S, Plaimee P, Sae-Teaw M. Dietary intake of melatonin from tropical fruit altered urinary excretion of 6sulfatoxymelatonin in healthy volunteers. J Agric Food Chem. 2013;61(4): 913-9.

144. Takata RH, Scheuer PJ. Ananasic acid: a new trihydroxytriterpenecarboxylic acid from pineapple stems. Tetrahedron. 1976;32(10):1077-80.

145. Ito S, Oshima Y. Studies on the tannin of Japanese persimmon (Diospyros Kaki L.). Agric. Biol Chem. 1962;26(3):156-61.

\section{Publisher's Note}

Springer Nature remains neutral with regard to jurisdictional claims in published maps and institutional affiliations.

Ready to submit your research? Choose BMC and benefit from:

- fast, convenient online submission

- thorough peer review by experienced researchers in your field

- rapid publication on acceptance

- support for research data, including large and complex data types

- gold Open Access which fosters wider collaboration and increased citations

- maximum visibility for your research: over $100 \mathrm{M}$ website views per year

At $\mathrm{BMC}$, research is always in progress.

Learn more biomedcentral.com/submissions 